\title{
Los diseños en la cestería seri. Ensayo sobre técnicas de vinculación social
}

\section{Designs in Seri Basketry: an Essay on Techniques of Social Relationships}

Artículo recibido el I9 de junio de 20I5; devuelto para revisión el 9 de diciembre de 20I5; aceptado el 29 de febrero de 20I6. http://dx.doi.org/IO.2220I/iie.I8703062e.20I6.109.2579

María Isabel Martínez Programa de Becas Posdoctorales, Coordinación de Humanidades,

Ramírez Universidad Nacional Autó noma de México, México.

isamartinez79@gmail.com

Líneas de investigación: El Estado mexicano desde la mirada de los rarámuri. La relación entre el desarrollo institucional del Estado mexicano durante los siglos xx y xxI; imagen, corporalidad y temporalidades indígenas en México.

Publicaciones más relevantes

Estudios sobre parentesco rarámuri y ranchero en el noroeste de México, coords. María Isabel Martínez y María Eugenia Olvarría (México: Universidad Autónoma Metropolitana/Porrúa, 20I2); "Tejiendo como caminos la vida social: teoría rarámuri de la socialidad y la persona”, en Hilando al norte: nudos, redes, vestidos, textiles, ed. Arturo Gutiérrez (México: El Colegio de San Luis, 20I2); coordinadora del número II2, de Artes de México: Tarahumaras. El camino, el hilo, la palabra (20I4).

Resumen El objeto de este artículo es describir, desde la organización del conocimiento y de la práctica de algunas tejedoras seris de El Desemboque, Sonora, qué significan los diseños en la cestería. Mostraré que éstos son a) índices de las relaciones que se establecen durante su elaboración y transmisión (la variación individual, la construcción del consenso familiar y de la "tradición") y b) técnicas de vinculación para producir, reproducir e intensificar su sociedad. Asimismo, exploro el problema de la variabilidad individual en la manufactura y denominación de los diseños, lo cual implica desplazar el análisis desde el significado de los diseños hacia el sentido otorgado por sus productoras dentro del contexto de uso y práctica.

Palabras clave seri; cestería de rollo; diseños en cestería; técnicas sociales; tradición; variación individual. 
Abstract With reference to the organization of knowledge and practice of some Seri weavers from El Desemboque, Sonora, this article addresses the meanings of the designs on their basketry. It identifies these as: I) indicators of relations established during the basketry production and transmission of knowledge (individual variation, building of family consensus and "tradition") and, 2) techniques of social bonding that help to produce, reproduce and intensify Seri society. The problem of individual variability in the manufacture and denomination of designs will also be explored, which means shifting the analysis from the general signification of the designs towards the meanings endowed on them by their creators within the context of their use and practice.

Keywords Seri, coil basketry, designs in basketry, tradition, individual variation. 
DOI: http://dx.doi.org/10.22201/iie.18703062e.2016.109.2579

\author{
MARÍA ISABEL MARTÍNEZ RAMÍREZ \\ PROGRAMA DE BECAS POSDOCTORALES \\ COORDINACIÓN DE HUMANIDADES
}

UNIVERSIDAD NACIONAL AUTÓNOMA DE MÉXICO

\title{
Los diseños en la cestería seri Ensayo sobre técnicas de vinculación social
}

$\mathrm{E}$ l objetivo de este artículo es describir, desde la organización del conocimiento y de la práctica, qué son los diseños en la cestería para las mujeres seris. Mostraré que al fungir como técnicas de vinculación social, los diseños condensan en su manufactura y figuración procedimientos de transmisión del conocimiento como el consenso parental, la "tradición" y la memoria, así como formas de producción social o de reproducción del colectivo, tales como la distinción individual, la variabilidad familiar y la intensificación de las relaciones con los no seris. ${ }^{I}$ Desde los ańos sesenta del siglo $\mathrm{xx}$, la cestería de rollo seri ha sido elaborada exclusivamente para su venta ${ }^{2}$ y el primer registro fotográfico de canastas con diseños data de principios del siglo pasado. ${ }^{3}$ Por ello, la literatura se ha concentrado en discernir el origen y el desarrollo de los

I. A lo largo de este texto haré uso de la noción de alteridad para referirme a los vínculos que los seris mantienen con otros seris no contemporáneos, tohono o’odham a quienes llaman pápago, mexicanos y estadounidenses. Advierto que la alteridad no necesariamente remite a relaciones interétnicas — puesto que me interesa explorar el punto de vista de algunas tejedoras seris, quienes no se conceptualizan a sí mismas ni a otros como una etnia- ni a relaciones interculturales -ya que la alteridad, como advertirá el lector, transita por aquello que es entendido por los seris como natural.

2. Thomas Bowen, "Seri", en Alfonso Ortiz, ed., Handbook of North American Indians (Washington: Smithsonian Institution, 1983), 239.

3. Federico García y Alva, "La expedición a la isla Tiburón de 1904, 'las manos yaqui'”, Raza seri (Sonora: Directorio del Estado de Sonora, Hermosillo, 1905), consultado el 3 de mayo de 20I5, http://clima.dicym.uson.mx/archivo/misces/articulos/expedicionı904.htm. 
diseños a partir de la mercantilización de la cestería ${ }^{4}$ y en explicar la variación individual de su producción y denominación, entendida como descriptiva, inconsistente y carente de significado. ${ }^{5}$

El tránsito de un valor simbólico, ceremonial, mágico y chamánico, hacia un uso ornamental y utilitario asociado con contextos mercantiles o decorativos ha sido recurrente para explicar éstas y otras producciones gráficas de los seris, como la pintura facial ${ }^{6}$ y los diseños pintados en la cerámica. ${ }^{7}$ Como la manifestación de un proceso más amplio de aculturación ${ }^{8}$ y desintegración de un sistema de creencias, ${ }^{9}$ se ha descrito cómo estas expresiones se liberan de su contenido simbólico para adquirir un carácter ornamental, cuyo fin sería la producción de objetos más bellos para la venta ${ }^{\mathrm{IO}} \mathrm{o}$ para el adorno personal. ${ }^{\mathrm{II}}$

Durante el siglo xx, el estilo de vida de los seris, fundamentado en la caza, la pesca y la recolección, la ocupación del territorio en campamentos ${ }^{\mathrm{I2}} \mathrm{y}$ una organización en unidades sociales diferenciadas, cambió. ${ }^{13}$ Este proceso de in-

4. Margarita Nolasco, "Los seris, desierto y mar", Anales del INAH, vol. i8 (1967): I50; Berenice Johnston, The Seri Indians of Sonora Mexico (Tucson: University of Arizona Press, 1980 [1970]), 8; Edward Moser, "Seri Basketry", The Kiva 38, núms. 3 y 4 (1973): I30; Richard S. Felger y Mary B. Moser, People of the Desert and Sea: Ethnobotany of the Seri Indians (Tucson: University of Arizona Press, 1985), 195; Seth M. Schindler, "The Material Culture and Technoeconomic View System of the Seri Indians: an Experimental Reconstruction", tesis de doctorado (Southern Illinois University, 198I), $4 \mathrm{I} 6$.

5. Schindler, "The Material Culture," 406.

6. Gwyneth Harrington Xavier, "Seri Face Painting", The Kiva II, núm. 2 (1946): 19; Nolasco, "Los seris, desierto y mar", I50; Edward Moser y Richard S. White Jr., "Seri Clay Figurines", The Kiva 33, núm. 3 (1968): I46; Schindler, "The Material Culture”, 407; Gabriela Robledo Hernández, Los seris (México: Instituto Nacional Indigenista, 198I), s. p.

7. Thomas Bowen y Edward Moser, "Seri Pottery", The Kiva 33, núm. 3 (1968): IIO-III.

8. Moser, "Seri Basketry", I38.

9. Bowen, "Seri”, 247.

Io. Bowen y Moser, "Seri Pottery", III.

II. Xavier, "Seri Face Painting”, I9; Nolasco, "Los seris, desierto y mar", I50.

I2. Edward H. Spicer, "Seris", en Cycles of Conquest. The Impact of Spain, Mexico, and the United States of the Indians of the Southwest, I533-1960 (Tucson: The University of Arizona Press, 1997 [1962]), II4-II7; William B. Griffen, Notes of Seri Indian Culture Sonora, Mexico, Latin American Monographs io (Gainesville: University of Florida Press, I959), I-5; William B. Griffen, "A Survey of Present Day Seri Culture", tesis de maestría (Mexico City College-Centro de Estudios Universitarios, I955), I-I2; Bowen, "Seri”, 235; Felger y Moser, People of the Desert and Sea, I4-I9.

13. Edward Moser, "Bandas seris", Calafia, núm. 3 (1976); Spicer, "Seris"; Griffen, Notes of Seri Indian Culture Sonora, I-5; Griffen, "A Survey of Present Day Seri Culture", I-I2. 
tegración y dependencia a una economía monetaria y capitalista, ${ }^{14}$ seguido por campañas de evangelización que iniciaron en la década de $1960,{ }^{15}$ ha sido entendido como: una mudanza radical e impuesta por diversas políticas de despojo y exterminio o como un cambio gradual motivado por el interés de los seris en el acceso a bienes de servicio como el agua, el desarrollo de la pesca comercial y la venta de artesanías. ${ }^{16}$ Cada perspectiva ofrece versiones más o menos distintas que será preciso revisar críticamente en otro lugar. Como anotó Marshall Sahlins,${ }^{17}$ cuyo interés sigo, en este texto me interesa reflexionar sobre la manera en que los seris extrajeron sus condiciones de existencia con el fin de complejizar nuestras narrativas y su lugar en ellas.

Así, los problemas sobre los diseños en la cestería seri, como plantearon Seth M. Schindler ${ }^{18}$ y Edward Moser ${ }^{19}$ al entenderlos como el producto de influencias externas por sus rasgos gráficos o al clasificarlos por asociación con contextos ceremoniales y comerciales, no se limitan a un análisis formal y de los estilos, y como discutiré adelante, retomarlos implica ir más allá de ellos. Como advirtieron estos autores, la variación individual es constitutiva de la producción y denominación de los diseños, pero nuestra comprensión no puede reducirse a una lectura idiosincrática ${ }^{20} \mathrm{o}$ utilitaria. ${ }^{2 \mathrm{I}}$ La distinción propuesta por Franz Boas ${ }^{22}$ entre el elemento gráfico y el plástico, así como entre el valor formal y el valor estético, fue cuestionada desde la antropología por Claude

I4. Nolasco, "Los seris, desierto y mar", I5I-I53; Maya Lorena Pérez Ruiz, Seris, Colección Pueblos Indígenas de México (México: Instituto Nacional Indigenista, I993), 8-II; Maya Lorena Pérez Ruiz, "Seris", en Etnografía contemporánea de los pueblos indígenas de México (México: Instituto Nacional Indigenista-Secretaría de Desarrollo Social, 1995), 73; Robledo Hernández, Los seris.

I5. Spicer, "Seris", II7; Rodrigo Rentería, Seris. Pueblos indígenas del México contemporáneo (México: Comisión Nacional para el Desarrollo de los Pueblos Indígenas, 2007), 20.

I6. Felger y Moser, People of the Desert and Sea, I7-I9; Stephen A. Marlett, "Introduction", en A Grammar of Seri, última modificación 20 de septiembre de 2010 , consultado el 27 de marzo de 20I5, www.und.nodak.edu/instruct/smarlett/Stephen_Marlett/GrammarDraft.html, 37; Carolyn O’Meara, "Seri Landscape Classification and Spatial Reference”, tesis de doctorado (Nueva York: University at Buffalo, 2010), 15-20.

17. Marshall Sahlins, "O 'pessimismo sentimental' e a experiência etnográfica: por que a cultura não é um 'objeto’ em via de extinção (parte I)”, Mana 3, núm. I (I997): 5I, 53.

I8. Schindler, "The Material Culture".

19. Moser, "Seri Basketry".

20. Schindler, "The Material Culture", 408.

2I. Moser, "Seri Basketry", I22, I3O.

22. Franz Boas, El arte primitivo, trad. Adrián Recinos (México: Fondo de Cultura Económica, 1947 [1927]), 94 . 
Lévi-Strauss, ${ }^{23}$ quien al postular su integración, abrió un campo de indagación hacia otras ontologías, es decir, al estudio de otros existentes, como utensiliosornamentos, objetos-animales o cajas-que-hablan y, en consecuencia, al conocimiento de lógicas-prácticas distintas. Por ello, parafraseando a este autor, describiré qué son estos diseños para las mujeres seris, considerando que las canastas no son objetos preexistentes que se decoran a posteriori con el fin de ser objetos de venta. Por el contrario, solamente logran su existencia definitiva (técnicas de vinculación social) mediante la integración del decorado (diseños) y la función utilitaria (objetos de venta). Para lograrlo, durante el trabajo de campo que realicé en los inviernos de 2013 y 2014 en El Desemboque del Río San Ignacio o de los Seris, municipio de Pitiquito, Sonora, México, ${ }^{24}$ los diseños funcionaron como un vínculo de relaciones por medio del cual se cocrearon ${ }^{25}$ métodos de indagación junto con las tejedoras seris. ${ }^{26}$ Es decir, mediante un proceso de reflexividad mutua donde construimos herramientas de investigación a partir de formular preguntas conjuntamente, conocí parte de la "organización del conocimiento y práctica" 27 de estas mujeres, exploré el "rendimiento epistemológico y conceptual de los diseños" ${ }^{28}$ y determinamos las premisas para su análisis. Por ello, como las tejedoras seris lo manifestaron y como lo indicaron otros autores para distintos casos en Amazonía, ${ }^{29}$

23. Claude Lévi-Strauss, "El desdoblamiento de la representación en el arte de Asia y América", en Antropología Estructural (Barcelona: Páidos, 2013[1974]), 282.

24. La información contenida en este artículo se fundamenta en estas dos estancias que suman nueve semanas de campo.

25. Si bien Roy Wagner habla de invención y por tanto de coinvención siguiendo su propuesta y considerando los procesos de producción del conocimiento en este texto hablaré de co-creación, Roy Wagner, The Invention of Culture [The University of Virginia Press, 1975], 17-I8).

26. En este proyecto participaron Francisca y Marta Morales, Ana Torres, Aurelia Molina, Martha Monroy, Berta Estrella, María Luisa Astorga, Ana Victoria Rodríguez, Adriana Estrella Romero, Ángela Torres Cubias, María Luisa Molina, Genoveva Hoeffer Félix, Raquel Hoeffer Félix, María de Jesús Félix Molina (Carolina) y Lourdes Hoeffer Félix.

27. Sahlins, "O 'pessimismo sentimental'".

28. Pedro Cesarino, "A escrita e os corpos desenhados: transformaçóes do conhecimento xamanístico entre os Marubo", Revista da Antropologia 55, núm. I (2012): 77.

29. Anne-Christine Taylor, "Les Masques de la mémoire: essai sur la fonction des peintures corporelles jivaro", L'Homme, núm. I65 (2003), 223-248; Pierre Déléage, "Les Répertoires graphiques amazoniennes", Journal de la Société des Américanistes 93, núm. I (2007), 744-764; Cesarino, "A escrita e os corpos", 74-I39. 
en América del Norte ${ }^{30}$ y en México ${ }^{31}$ fue preciso explorar los modos internos de categorización, de fabricación y producción de los diseños, comprender su contexto de transmisión, los campos de sociabilidad implicados y reconocer hacia quién estaban dirigidos, entenderlos en fin como técnicas de vinculación social.

Además, fue necesario atender a las críticas sobre el simbolismo en la antropología del $\operatorname{arte}^{32}$ y reconocer que no me encontraba ante tropos visuales simbólicos que al ser definidos como textos culturales ${ }^{33}$ me conducirían irremediablemente a declarar, junto con otros autores, sobre la existencia de un simbolismo inerte o muerto, ${ }^{34}$ ya que como para otras producciones gráficas seris, ${ }^{35}$ al ser cuestionados explícitamente sobre el simbolismo de los diseños en la cestería, las tejedoras aludían exclusivamente a su belleza. Si, de forma alterna, presuponía que la producción de los diseños en la cestería no tenía por finalidad generar significados sino relaciones de sentido entre el objeto y la realidad ${ }^{36}$ — definida desde los términos de sus productoras, en tanto que el tejido es una labor exclusiva de las mujeres y esto particulariza las formas de producción social que describiré-, entonces aquello que debía cuestionar era en qué consistía esa categoría de belleza y cómo se articulaba con la transmisión del conocimiento y la producción social.

Finalmente, mediante el registro de léxico de formas de canastas y diseńos advertí que, a diferencia de otros conceptos nativos de imagen documen-

30. Carlo Severi, "Une Forme mnémonique amérindienne. Pictographie et Parallélisme”, en Le Principe de la Chimère (París: Rue d'Ulm/Musée du Quai Branly, 2007); Pierre Déléage, "Les Pictographies narratives amérindiennes", en Christian Jacob, ed., Les Mains de l'intellect, Lieux de Savoir 2 (París: Albin Michel, 20II).

3I. Johannes Neurath, La vida de las imágenes (México: Artes de México, 20I4); Diana Magaloni, Los colores del nuevo mundo. Artistas, materiales y la creación del Códice florentino (México: Universidad Nacional Autónoma de México/The Getty Research Institute, 20I4).

32. Cesarino, "A escrita e os corpos desenhados", I06-II8; Els Lagrou, "O que nos diz a arte kaxinawá sobre a relação entre identidade e alteridade?”, Mana 8, núm. I (2002), 45-53.

33. Cesarino, "A escrita e os corpos desenhados", II4.

34. Severi, "Une Forme mnémonique amérindienne", ios.

35. Xavier, "Seri Face Painting”, I9; Bowen y Moser, "Seri Pottery", IIo; Moser y White, "Seri Clay Figurines", 143.

36. Véase Claude Lévi-Strauss, "La ciencia de lo concreto", en El pensamiento salvaje, trad. Francisco González Aramburu (México: Fondo de Cultura Económica, 2006 [196I]), 95-96, I24, I26, I37. 
tados en México ${ }^{37}$ y en Amazonía, ${ }^{38}$ el verbo en cmiique iitom para hablar de los diseños (cahóospoj) ${ }^{39}$ remitía a una técnica que durante el tejido producía simultáneamente diseños y vínculos sociales. Los denominaré técnicas porque ambos se fabrican y su condición de existencia es mutua. ${ }^{40}$

La cestería de rollo manufacturada por las mujeres seris o comcaac que habitan los poblados de Punta Chueca (Socaaix), municipio de Hermosillo, y El Desemboque (Haxöl Iihom) se teje con una técnica de enroscamiento simple

37. Como el nierika huichol, definido como objetos, imágenes, el "don de ver" o la "habilidad visionaria". Neurath, La vida de las imágenes, 6I.

38. Por ejemplo, los xapiripë yanomami, imágenes de imágenes que se multiplican como espejos o cristales y cuya traducción más cercana es espiritu. Véase Eduardo Viveiros de Castro, "A floresta de cristal: notas sobre a ontologia dos espíritos amazônicos", Cadernos de campo, núms. I4/I5 (2006); Els Lagrou, "Existiria um arte das sociedades contra o Estado?", Revista da Antropologia 54 , núm. 2 (20II). Otro caso ejemplar son los patrones gráficos de los marubo como el yochi que remite nuevamente a los espíritus y a un instrumento chamánico de transformación. Cesarino, "A escrita e os corpos desenhados." Finalmente puedo mencionar el kene, dami y yuxin kaxinawá que implican también la transformación. Els Lagrou, "Perspectivismo, animismo y quimeras: una reflexión sobre el grafismo amerindio como técnica de alternación de la percepción”, Mundo Amazónico, núm. 3 (20I2): II3.

39. Para la escritura de la lengua seri o cmiique iitom utilizaré la ortografía empleada en Mary B. Moser y Stephen A. Marlett, comps., Comcaac quih yaza quih hant ihiip hac: Diccionario seriespañol-inglés (México: Plaza y Valdés/Universidad de Sonora, 2005), de donde tomo los siguientes ejemplos. En sus derivaciones, este verbo se utiliza para referirse a la escritura y las fotografías (caaspoj), superficies con dibujos o pintados (coospoj) y diversos animales, insectos o moluscos manchados (raya águila, hatip coospoj, pez gallo, ctomliispoj, mariposa monarca, seneliispoj, lenguado, caasquim coospoj, almeja china, spiitcam coospoj, jaguar, xazoj coospoj, o que con su movimiento dibujan la arena, hant iti yeemej coospoj).

40. Respecto a otras reflexiones sobre técnica, tecnología, máquinas y antropología del arte en México véase Alejandro Fujigaki, "La disolución de la muerte y el sacrificio. Contrastes de las máquinas de transformaciones y mediaciones de los rarámuri y los mexicas", tesis de doctorado (Universidad Nacional Autónoma de México, 2015), I-47; Alejandro Fujigaki, "Construir el camino del olvido. Rituales mortuorios", Artes de México. Tarahumaras. El camino, el hilo, palabra, núm. II2 (20I4); Federico Navarrete, "Máquinas para dar forma al tiempo, los monolitos mexicas" (ponencia presentada en el Coloquio Experiencias Temporales y Formas de la Memoria. Una Perspectiva Comparativa, Instituto de Investigaciones Históricas, Universidad Nacional Autónoma de México, D.F., 22 y 23 de mayo de 20I4), s.p.; Antonio Jaramillo, "La cuenca del Caribe como unidad diversa: el juego de pelota, una máquina para lidiar con la alteridad", en Raúl Román Romero, Jorge Elías Caro y Antonio Vidal, comps., Sistemas Políticos, Relaciones Internacionales e Identidades. Memorias III Congreso Internacional de Estudios Caribeños (San Andrés Isla: Universidad Nacional de Colombia, 2014), 228-253. 
de anillos cerrados o abiertos que recubre un fajo fundacional en sentido antihorario. El rollo se perfora desde el exterior generando, con una calidad similar, el mismo diseño y tejido en ambas caras. Para elaborar una canasta se recolecta el torote —en lengua seri haat (Jatropha cuneata)—, se queman y descascaran las ramas, procesan las fibras (en dos fases: elaboración de zeee y de hamizj), producen las tinturas, se tiñen las fibras y tejen (figs. Ia-If)..$^{4 \mathrm{r}}$ Las canastas con diseños y sin ellos se manufacturan de la misma manera. El nudo y el inicio del canasto son el punto de fuga para tejer los diseños, a partir de ellos se cuentan los puntos que definen su distribución y posición.

En estos poblados, donde residen cerca de 900 personas, ${ }^{42}$ una de las principales fuentes de ingresos económicos para mujeres ha sido la comercialización de la cestería. Durante los años cincuenta y sesenta del siglo xx, la producción de la cestería transitó de los usos domésticos y ceremoniales hacia la venta. Mo$\operatorname{ser}^{43}$ describió este proceso como aculturación ya que su venta contribuía con la adaptación de los seris en una economía monetaria y la demanda de los compradores estimulaba cambios plásticos y técnicos en su manufactura. Bajo

4I. Sobre el registro de manufactura de cestería de rollo seri, además de la información detallada de Moser, "Seri Basketry"; véase Felger y Moser, People of the Desert and Sea, 179-206; véase Richard S. Felger y Mary B. Moser, "El espíritu de los coritas seris", Artes de México. Cestería, núm. 38 (1997): 44-49, en Barbara Johnson, "Seri Indian Basketry”, The Kiva 25, núm. I (1959): IO-I3; y William Smith, "Observations Regarding Seri Indian Basketry", The Kiva 25, núm. I (1959): I4-I7, quienes publicaron algunas anotaciones breves sobre cestería, así como William McGee, Los seris (México: Instituto Nacional Indigenista, 1980 [1898]), 347-348. Recientemente he discutido los procesos de permanencia y cambio en la cestería - María Isabel Martínez Ramírez, "Pensando a través de la cestería seri: permanencia, innovación y memoria" (en prensa). En décadas recientes es posible destacar el trabajo de David Burckhalter, Among Turtle Hunters and Basket Makers: Adventures with the Seri Indians (Tucson: Treasure Chest Books, 1999), 45-66, quien desde 1970 realiza visitas a esta región, y los trabajos de Donaciano Gutiérrez, "Cestería seri”, en Efraín Cortés Ruiz y Catalina Rodríguez Lazcano, coords., Tejedores de la naturaleza en cinco regiones de México (México: Instituto Nacional de Antropología e Historia, 1999), I63-176, y Alejandro Aguilar Zeleny, "Con la memoria en las manos. La artesanía de los pueblos originarios de Sonora. Saaptim. Hilando los arbustos del desierto, la cestería y otros símbolos", Correo del Maestro, núm. 2II (2013), 47-55. Otros autores cuentan con descripciones breves dentro de trabajos generales como Nolasco, "Los seris, desierto y mar", I63-I7I; Griffen, Notes of Seri Indian Culture Sonora, I26-I3I; Griffen, "A Survey of Present Day Seri Culture", 22-27; Johnston, The Seri Indians of Sonora, 8-9; Arturo José Cuéllar, La comunidad primitiva y las políticas de desarrollo. (El caso seri) (Universidad Nacional Autónoma de México, I980), I09-II4; Pérez Ruiz, Seris, I6; y Rentería, Seris, 2I-25.

42. O’Meara, "Seri Landscape Classification and Spatial Reference”, I5.

43. Moser, "Seri Basketry", 138. 
esta visión, las canastas son definidas como un objeto mercantil. Algunos autores las describen como un objeto artesanal y afirman que forman parte de un "sistema de creencias desintegrado" 44 donde las relaciones de venta generan el despliegue de las habilidades artísticas de las mujeres seris, ${ }^{45}$ como si los vínculos con el mercado fuesen su condición de existencia, o bien que su producción se enmarca en la cristalización de un capitalismo mercantil dentro del cual se destacan actitudes empresariales por parte de los seris. ${ }^{46}$ En contraposición, desde la perspectiva de Donacio Gutiérrez ${ }^{47}$ y Alejandro Aguilar ${ }^{48}$ la cestería, al entenderse como una actividad prehispánica, es una práctica ancestral integrada a un simbolismo que ha sido importante para su conservación.

En otro texto he discutido ${ }^{49}$ cómo implícitamente ambas posiciones comparten la premisa donde el conocimiento seri sobre la cestería sería un tipo de thesaurus de origen endógeno. ${ }^{50}$ De tal manera que su permanencia testimoniaría su continuidad y sus modificaciones entrañarían una irrupción exógena, cancelando la posibilidad de que estos conocimientos no sean necesariamente antiguos y que aquello que permanezca no sean contenidos o referentes, sino los procedimientos para su producción. Uno de los efectos de esta premisa es que las explicaciones para la permanencia y los cambios técnicos o plásticos de las canastas aludan tendencialmente a factores ajenos a las motivaciones de los seris, al extraer la cestería de su campo de producción, de discurso y de la organización del conocimiento y de la práctica a los que pertenece.

La relación entre los contextos mercantiles y la producción de la cestería seri ha sido un argumento central en la literatura que me antecede para explicar los procesos de cambio y permanencia en su manufactura, así como para determinar que los diseños tejidos en las canastas carecen de un valor simbólico. Al considerar estos vínculos, así como el resto de las transformaciones sociales por las que han transitado los seris durante el siglo xx, el objetivo de este artículo es explorar la perspectiva de las tejedoras. En consecuencia, desplazar la discusión del significado simbólico de los diseńos tejidos en las canastas hacia el sentido

44. Bowen, "Seri", 247.

45. Felger y Moser, People of the Desert and Sea, 179.

46. Cuéllar, La comunidad primitiva y las politicas de desarrollo (El caso seri), I6.

47. Gutiérrez, "Cestería seri".

48. Aguilar, "Con la memoria en las manos".

49. Martínez, "Pensando a través de la cestería seri".

50. Manuela Carneiro da Cunha, "'Cultura’ e Cultura: conhecimentos tradicionais e direitos intelectuais”, en Cultura com aspas (Brasil: Cosac Naify 2014 [2009]), 364. 


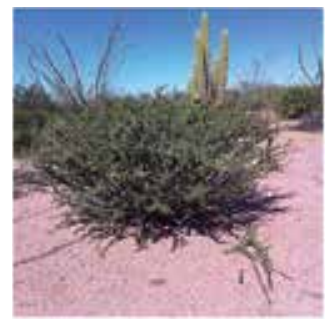

a

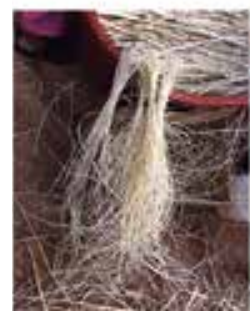

d

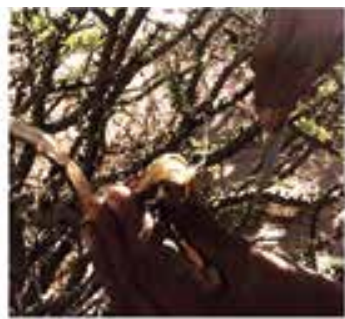

b

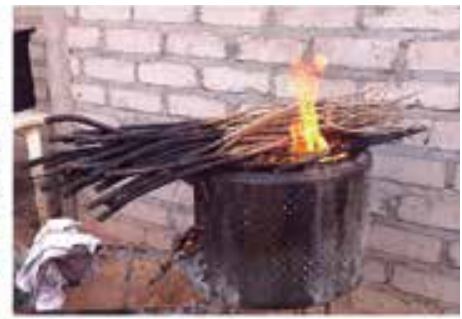

c

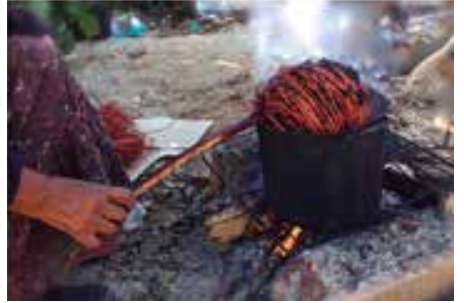

$\mathrm{e}$

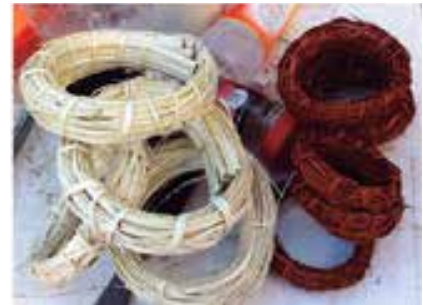

f

I. Procesos de manufactura de las fibras de torote para producir cestería de rollo: a) arbusto de torote; b) prueba de flexibilidad de las ramas durante la recolección por Aurelia Molina; c) quema por Martha Monroy; d) zeee o fibras para tejer el interior del rollo, elaboradas por Martha Monroy; e) teñido con la raíz heepol por Ana Torres; f) rollo con hamizj crudo y teñido de heepol por Berta Estrella. Fotos: María Isabel Martínez Ramírez.

otorgado por sus productoras dentro del contexto de uso y práctica a partir de los métodos que construimos conjuntamente.

\section{Entre frases, nombres y diseños: reflexión sobre el levantamiento del léxico}

El punto de partida de esta investigación fue la configuración de una base de datos representativa de la cestería durante la segunda mitad del siglo xx. Ésta se conformó con 2I fotografías de canastas de la Colección Etnográfica del Museo Nacional de Antropología (MNA) ${ }^{5 \mathrm{I}}$ y 35 imágenes del artículo de Moser, "Seri

5I. La visita al Museo Nacional de Antropología se realizó el ro de octubre de 20I3. Agradezco a Leopoldo Trejo su ayuda para la realización de dicha base de datos, así como a Sergio Torres, encargado del Acervo de Antropología, y a Carolyn O’Meara del Instituto de Investigaciones Filológicas, unam. De acuerdo con las fichas de catalogación, la mayoría de las piezas ingresaron a la colección en 1978,1985 y 1999. 


\section{I46 MARÍA ISABEL MARTÍNEZ RAMÍREZ}

Basketry." El objetivo era conocer el léxico para describir las formas y los diseños de las canastas. ${ }^{52}$

Uno de los resultados permitió identificar que, como en otras tradiciones gráficas documentadas en América, ${ }^{53}$ para las mujeres seris la relación entre las frases nominales y los diseños no era reductible a la representación, producida para su interpretación ni conformaba un diccionario de símbolos. Esta articulación expresaba vínculos sociales a partir de tres formas de producción: por figuración ${ }^{54}$ (7.I4 por ciento de la muestra), por invención 55 (7.I4 por ciento) y por reconocimiento posterior por analogía ${ }^{56}$ (85.7 por ciento).

Ejemplos de la primera son los registros: canasta en forma de plato diseñada con manta raya (hasaj hatip cöcoospoj) y canasta en forma de plato con diseño de flor de incienso (hasaj yaspoj hehe yapxöt cotx) (fig. 2a). ${ }^{57}$ Para corroborar la

52. El procedimiento para el levantamiento de datos consistió en una serie de preguntas en cmiique iitom a las que respondía una tejedora seguida por la traducción simultánea de la intérprete traductora. Yo les mostraba las imágenes de la base de datos y procedíamos al cuestionario. Las entrevistas las transcribí en campo junto con Debora Perales, quien corregía el documento e incluía información sobre la cestería y sus diseños.

53. Déléage, "Les Pictographies narratives amérindiennes", 97-I04; Cesarino, "A escrita e os corpos desenhados", I04-II8; Taylor, "Les Masques de la mémoire”, 305-309; Severi, "Une Forme mnémonique amérindienne", 98-II4.

54. Por su simplicidad conceptual, utilizo el término figuración para referirme a lo que ciertos autores han calificado como representación. A diferencia de ésta, que supone una serie de operaciones cognitivas y fenomenológicas, así como ciertas epistemologías y ontologías que están siendo revisadas críticamente, la figuración es un tipo de producción donde cada artista reproduce lo que considera real.

55. Por invención se entiende un vínculo personalizado entre la productora y los diseños, que como las tejedoras señalan, surgen de su mente.

56. El reconocimiento posterior por analogía trata sobre la relación que se genera a partir de la evidencia visual común entre un diseño y otra imagen mediante una relación indexical. A diferencia de la figuración, este vínculo no sucede entre un objeto y su representación, sino entre dos figuraciones enlazadas a partir de una memoria parental.

57. Los dibujos a línea son míos, éstos siguen el patrón del tejido de cestería de rollo seri, ya que son reproducciones de: a) algunas fotografías de las colecciones etnográficas del Museo Nacional de Antropología de la Ciudad de México y del Arizona State Museum; o b) algunas imágenes del artículo de Edward Moser (vid n. 4). Estos dibujos reproducen el diseńo sobre el tejido por tres motivos. En primer lugar, como se argumenta a lo largo de este texto, la comprensión del diseño depende de su materialidad. En segundo, al realizar dibujos a línea continua, en ocasiones, los diseños se modificaban y, finalmente, la información presentada en este artículo se fundamenta en el conocimiento cocreado con algunas tejedoras seris de El Desemboque. Modificar estas imágenes implicaría alterar las condiciones de producción de dicho conocimiento. 
figuración, las mujeres me mostraron fotos de sus colecciones personales. A lo largo de nuestras caminatas por el desierto o la playa me indicaron los animales y plantas tejidos, manifestando un lazo con su entorno, el cual, como han advertido Stephen A. Marlett ${ }^{58}$ y Carolyn O'Meara, ${ }^{59}$ no se percibe como un sitio duro o desagradable, tal como podría ser para quien lo desconoce y lo definiría por su aparente escasez de recursos, así como por sus temperaturas extremas. La segunda forma de producción, la invención, surgía "de la mente" de cada mujer, generalmente combinaciones de patrones geométricos (fig. $2 \mathrm{~b}$ ).

La tercera forma, reconocimiento posterior por analogía, la analizó AnneChristine Taylor ${ }^{60}$ entre los shuar o achuar y Pierre Déléage ${ }^{6 \mathrm{I}}$ entre los sharanaua, en ambos casos el lazo entre los nombres y los diseños era un índice mnemotécnico. Para los shuar y achuar, los diseños eran la marca o el índice del encuentro individual entre un muerto y un guerrero que generaba vínculos de memoria y olvido colectivos. Así, el reconocimiento entre la semejanza de las pinturas corporales y los diseńos, por ejemplo, de alguna serpiente, era posterior a dicho encuentro. Para los seris, este proceso analógico englobaba motivos geométricos (ondulado, cocömonjc, tener forma dentada, catéemloj, tener forma de gancho, queefe, rayado, cocpátyax), en ocasiones reconocidos como diseños (diseño en forma de red, cool yaspoj, con anillos, cöcaafija, y en espiral, cocpaaija), estrellas (izoj canoj), flores (hehe yapxöt) y diseńos retomados por los tohono o'odham también denominados pápago. Como describiré, su designación era indicativa de la relación entre la tejedora y la fuente de transmisión del conocimiento (una mujer, las almejas piedreras o los pápago) (fig. 2c).

Al cuestionar la correspondencia como único método de comprensión de la relación entre la palabra y la imagen, algunos estudios han criticado el valor icónico, codificado, comunicativo, ilustrativo, decorativo y narrativo de las imágenes. En contraposición, al indagar criterios epistemológicos y ontológicos nativos, así como las formas de producción y por tanto la vinculación entre el ejercicio oral, los signos gráficos y el colectivo que lo emplea, se han documentado tecnologías de transformación, ${ }^{62}$ técnicas de memoria, ${ }^{63}$ estructuras

58. Marlett, "Introduction", 39.

59. O’Meara, "Seri Landscape Classification and Spatial Reference", 23.

6o. Taylor, "Les Masques de la mémoire".

6I. Déléage, "Les Pictographies narratives amérindiennes".

62. Cesarino, "A escrita e os corpos desenhados", I6-I8; Neurath, La vida de las imágenes.

63. Taylor, "Les Masques de la mémoire"; Severi, "Une Forme mnémonique amérindienne". 

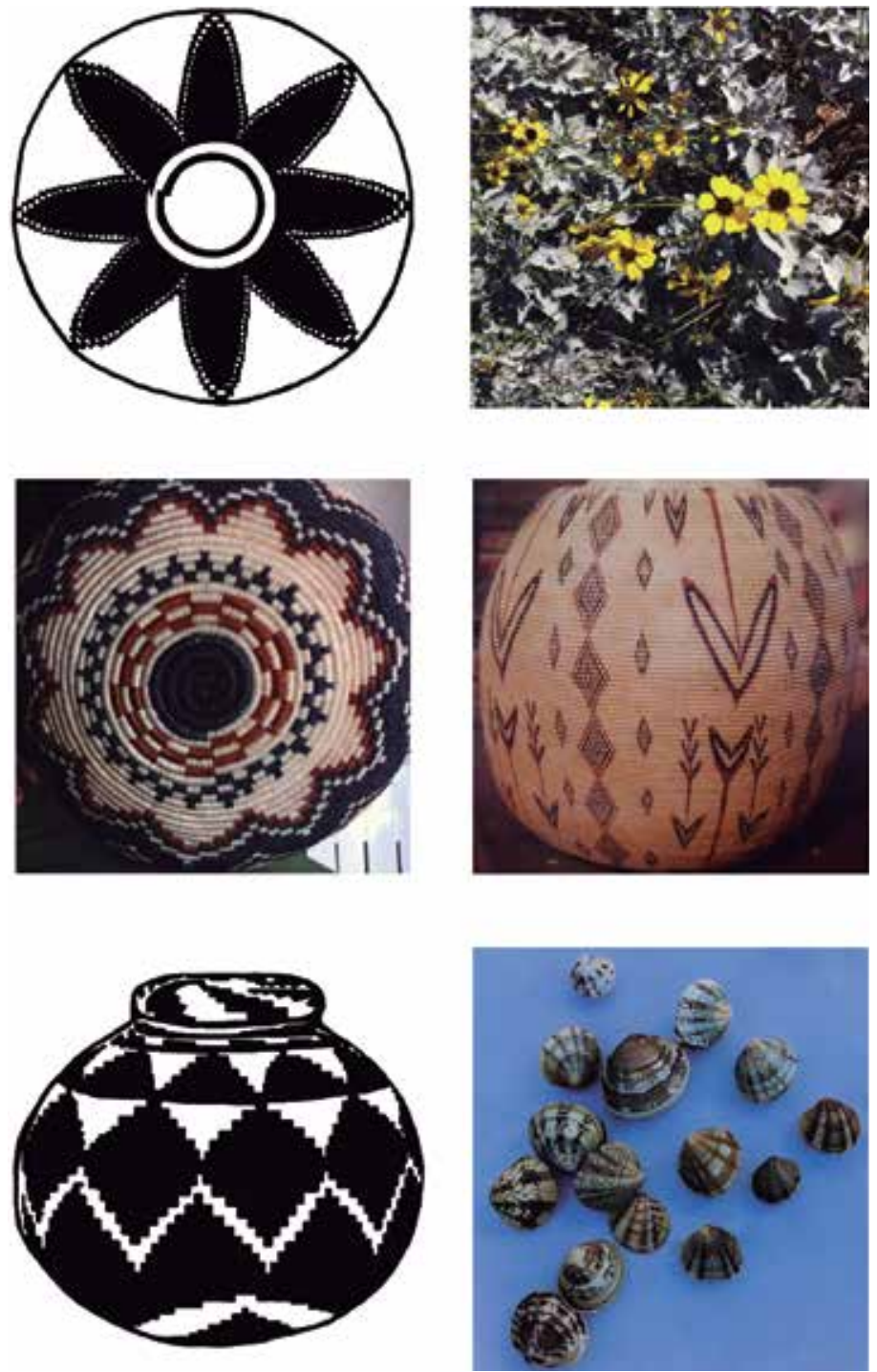

2. Tres formas de producción de los diseños que expresan vínculos sociales: a) figuración: la flor de incienso (Encelia farinosa), tomada de Moser, "Seri Basketry" (vid supra n. 4), fig. I3c; b) dos ejemplos de invención; c) reconocimiento posterior por analogía: en este caso almejas piedreras ( haxöl heecto, Leukoma grata), fig. I2b en Moser, "Seri Basketry" (vid supra n. 4). Agradezco la autorización de las mujeres de El Desemboque y Cathy Marlett para reproducir las imágenes. 
paralelísticas ${ }^{64} \mathrm{y}$ discursos de resistencia histórica. ${ }^{65} \mathrm{~A}$ partir del léxico de los diseños tejidos en la cestería seri puedo señalar la coexistencia de la figuración, la invención y el reconocimiento posterior por analogía para cuestionar que al privilegiar alguna de estas formas de producción se corre el riesgo de velar la complejidad de las tradiciones gráficas, generando una visión parcial. Resulta necesario reconocer que al menos en el caso seri la figuración es una forma de producción de los diseños, y preguntar cómo se articula con la invención y el reconocimiento posterior por analogía. ${ }^{66}$ Además, es preciso destacar que sea con el entorno, con la creatividad individual o con una fuente del saber, la relación entre los nombres y los diseños remite a técnicas de vinculación social. Éstas condensan procedimientos de transmisión del conocimiento, formas de producción y reproducción social, tanto al interior como al exterior de la sociedad seri.

\section{Los diseños como indices de relaciones: consenso familiar y "tradición"}

La variabilidad individual ${ }^{67}$ en la producción y denominación de los diseños en la cestería vinculó mis problemáticas y las de la literatura que me antecedía

64. Déléage, "Les Pictographies narratives amérindiennes".

65. Magaloni, Los colores del nuevo mundo; Silvia Rivera Cusicanqui, "Sociología de la imagen. Una visión desde la historia colonial andina”, en Chixi nakax utxiwa. Una reflexión sobre prácticas y discursos descolonizadores (Buenos Aires: Retazos y Tinta y Limón, 2010), 19-52.

66. E. Lagrou señaló el papel de la figuración en Amazonía como un camino óptico para la visualización de imágenes virtuales dentro del campo de la transformación. Lagrou, "Existiria um arte das sociedades contra o Estado?", 769; también J. Neurath destacó la coexistencia de la representación iconográfica y de la visión chamánica en los cuadros de estambre huicholes como dos operaciones artísticas que se establecen al contemplar la obra antes y después de la experiencia de nierika. Neurath, La vida de las imágenes, 95 .

67. La individualidad seri ha sido destacada y descrita por otros autores como Felger y Moser, People of the Desert and Sea, 196. Entendida en el marco de la manufactura de los diseños tejidos en las canastas será definida a lo largo del texto como una forma de producción social. Para una discusión sobre la problematización y reflexión crítica de esta categoría analítica en la antropología y su díada (la sociedad) véase Marilyn Strathern, O efeito etnográfico (São Paulo: Cosac Naify, 20I4); Marilyn Strathern, The Gender of the Gift. Problems with Women and Problems with Society in Melanesia (The University of California Press, 1988); y Roy Wagner, "The Fractal Person", en Maurice Godelier y Marilyn Strathern, eds., Big Men and Great Men (Cambridge University Press, I99I), I59-173. Para un estudio de caso sobre la construcción de la individualidad, como una categoría nativa, y su papel en la sociedad entre los rarámuri en México, véase María Isabel 
con las preocupaciones de las mujeres, ya que de las 56 fotografías que conformaron mi base de datos, sólo ocho descripciones coincidieron en el registro de las cinco mujeres que participaron en el registro léxico (figs. 3a-3h). Al cocrear métodos, las tejedoras de El Desemboque ofrecieron otras herramientas y plantearon preguntas distintas. En el proceso de transmisión sobre los diseños les interesaba definir el vínculo entre el conocimiento y la "tradición". Así, después del levantamiento de léxico, la bifurcación, entendida como un acontecimiento etnográfico capaz de alterar nuestras teorías, ${ }^{68}$ surgió una tarde, cuando dos tejedoras me comentaron que las frases de los diseños debían corregirse. Particularmente deseaban definir la distinción entre las estrellas y las flores, ya que al discutirlo con sus parientes por afinidad —a quienes consideraban con mayor conocimiento- discordaban. Organizaron reuniones familiares donde, a partir de las cualidades gráficas de los diseños, reflexionaron sobre esta distinción y llegaron a un acuerdo, determinado en gran medida por un hombre que consideraban con mayor conocimiento "tradicional": "las estrellas tienen cinco picos" y "las flores tienen menos o más pétalos".

$\mathrm{Al}$ proponer este método de indagación, las mujeres me mostraron una de las condiciones para la transmisión del conocimiento: el consenso familiar. Ésta, constitutiva de la manufactura de la cestería, configura un canon familiar que potencialmente genera variación durante la producción, ${ }^{69}$ y fue documentada durante el surgimiento y desarrollo de las tallas de palo fierro. ${ }^{70}$ De tal forma que la familia extensa sería el centro de la vida social seri, ${ }^{71}$ así como el eje rector de la transmisión del conocimiento y, por tanto, un campo potencial para

Martínez Ramírez, "Tejiendo como caminos la vida social: teoría rarámuri de la socialidad y la persona”, en Arturo Gutiérrez, ed., Hilando al norte: nudos, redes, vestidos y textiles (México: El Colegio de San Luis-El Colegio de la Frontera Norte, 20I2), 552-602. Entre los huicholes véase Johannes Neurath, "Alteridad constituyente y relaciones de tránsito en el ritual huichol: iniciación, antiiniciación y alianza", Cuicuilco I5, núm. 42 (2008), 29-44 y entre los nahuas, Marie Noelle Chamoux, "La Notion nahua d'individu: Un aspect du tonalli dans la región de Huachinango, Puebla”, en Guy Stresser-Péan y Dominique Michelet, coords., Enquêtes sur l'Amerique Moyenne (México: Instituto Nacional de Antropología e Historia/Consejo Nacional para la Cultura y las Artes/Centro de Estudios Mexicanos y Centroamericanos, 1989), 303-310.

68. Marilyn Strathern, "Binary License", Common Knowledge I7, núm. I (201I), 90.

69. Martínez, "Pensando a través de la cestería seri".

70. Berenice Johnston, "Seri Ironwood Carving", The Kiva 33, núm. 3 (1968), 164; Johnston, The Seri Indians of Sonora Mexico, I2; Felger y B. Moser, People of the Desert and Sea, I74; Schindler, "The Material Culture", 420; Pérez Ruiz, "Seris", 383.

7I. Felger y B. Moser, People of the Desert and Sea, 3. 

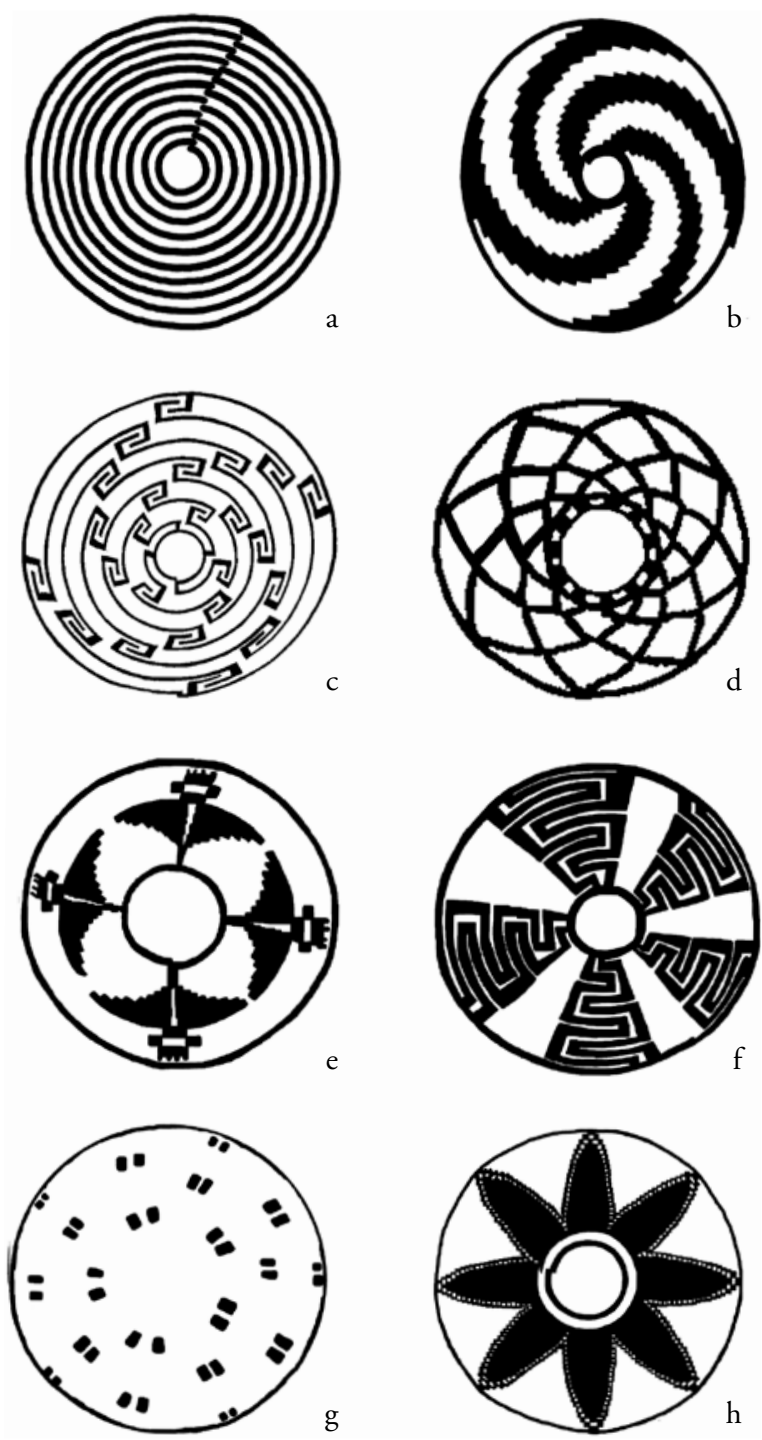

3. Ocho descripciones que coincidieron en el registro de las cinco mujeres que participaron en el registro léxico de diseños: a) con círculos (cöcaafija), fig. I2e; b) espiral (cocpaaija), fig. Iza; c) forma de gancho (queefe), fig. I2d; d) forma de red (cool), fig. I5b; e) manta raya (hatip), fig. I2b; f) ondulado (cocömonjc), fig. I6e; g) manchado (iti hapáhtolca), fig. I6e; h) flor de incienso (hehe yapxöt cotx), fig. I3c. Dibujos tomados de Moser, "Seri Basketry" (vid supra n. 4). 
engendrar su diversificación. Como una tejedora me indicó: "lo que te dicen en una familia es distinto a lo que te dicen en otra". Por este motivo, las mujeres de otros grupos familiares señalaron que las flores se distinguían de las estrellas porque tenían las puntas redondas mientras que los astros tenían picos. ¿Por qué era importante generar un consenso parental que simultáneamente producía variación?, ¿por qué aquel hombre con autoridad "tradicional" determinó el consenso del conocimiento que me transmitían sobre los diseños?

Al conversar con algunas personas de El Desemboque que constituyen un Consejo de Ancianos, ${ }^{72}$ generalmente señalaban que no todas las familias seris eran "tradicionales." Para definir su posición, en algunos casos aludían a su genealogía, donde no había matrimonios interétnicos (con indígenas o mestizos), resaltando la pureza familiar sobre la que se fundamentaba su conocimiento. La "tradición" se describía como conocimientos concretos en los que eran expertos (pintura facial, danza, cantos, astronomía), experiencias que habían atestiguado (forma de vida en la Isla Tiburón, uso de las canastas y de la cerámica) y aprendizajes heredados de sus padres. Su transmisión implicaba implícitamente una transformación. Un hombre que relató cómo durante su infancia y juventud había aprendido solo, es decir, observando e imitando durante la ejecución ritual, ha impartido clases de cantos, danzas y lengua "tradicionales" a nińos seris y a turistas, investigadores nacionales y extranjeros, así como a cualquier interesado sobre estos tópicos en un edificio conocido como la Escuela de Danza Tradicional Comcaac en El Desemboque. Narró cómo, ante la atracción de las nuevas generaciones por la escuela mexicana, consideró que la escolarización era el mejor método para transmitir la "tradición" —entendida por este anciano como "la enseñanza de los antepasados"-, e incluso al finalizar los cursos entregaba una credencial donde acreditaba a las personas como artistas "tradicionales." Otra mujer, a quien pregunté si las canastas se utilizaban en alguna ceremonia o fiesta, respondió: "sí usamos las canastas para las fiestas, como en el Año Nuevo, para que la gente que viene de fuera vea como se hacía antes".

He colocado entre comillas "tradición" para destacar el proceso de apropiación que los seris han hecho de este término. Como categoría de ida y vuelta ${ }^{73}$ ha sido utilizada por estos ancianos para hablar de una serie de conocimientos

72. De acuerdo con Pérez Ruiz (Seris, 392), es posible que este Consejo de Ancianos sea la forma actual del Consejo Supremo que se conformó y registró en 1969 promovido, junto con la constitución de un gobernador tradicional, por el Consejo Nacional de Comunidades Indígenas (CNC).

73. Manuela Carneiro da Cunha, "'Cultura’ e Cultura: conhecimentos tradicionais e direitos intelectuais", $3 \mathrm{I} 2$. 
concretos y de relaciones exclusivas que los vinculan por parentesco, corporalidad y experiencia —empírica o transmitida — con ciertos eventos que remiten a un tiempo que consideran antiguo. ${ }^{74}$ Esto cimenta su autoridad para transmitir contenidos concretos, como la definición de los diseños y la distinción entre las estrellas y las flores, y para transformar los procedimientos de su reproducción. Incluso, esta autoridad "tradicional" es una potencia para modificar contenidos concretos. Por ejemplo, al comparar mi registro de léxico con el de Moser ${ }^{75}$ y Schindler ${ }^{76}$ advertí que el diseño mariposa (seenel), reportado como un motivo tradicional 77 y como de reciente introducción, ${ }^{78}$ lo identificaban algunas tejedoras como manta raya y la manufactura era atribuida a sus madres. De igual manera, los diseños que Schindler ${ }^{79}$ identificó con motivos de origen pápago y apache fueron reconocidos como "tradicionales" (cool, bolsa de red, cöcaafija, hecho con círculos, y cocpaaija, espiral) (figs. 3a-3h). En este sentido es preciso ir más allá del análisis formal y de los estilos y, al atender los cuestionamientos cocreados con las mujeres seris, dar cuenta de la transmisión del conocimiento y de la conformación del consenso.

Además, esto explica por qué, al comparar los resultados de mi registro léxico con los de estos autores el resultado parecía aleatorio. Aquello que alguna vez se experimentó como una invención o como un préstamo de los pápago, era reconocido como parte de la "tradición." El conocimiento sobre los diseños y la manufactura de la cestería, tal como he discutido en otro texto al analizar

74. Pese a la aparente semejanza con la propuesta de Eric J. Hobsbawn, "Introduction: Inventing Traditions", en Eric J. Hobsbawn y Terence Ranger, eds., The Invention of the Tradition (Cambridge University Press, I983), I-I4, sobre las tradiciones inventadas, aquí la tradición no se entiende como una ficción en tanto que tiene efectos concretos. Tampoco es posible distinguir, como este autor lo propone, entre tradición y costumbre, ya que el fundamento del análisis son categorías nativas. De hecho, éstas no se contraponen necesariamente con la variabilidad, sino que resultan constitutivas como ha documentado la literatura etnográfica y describiré en este texto. Contrapuesta a las ideas de este autor, la etnografía del siglo xx ha demostrado que la convención, e incluso aquello que llamamos pasado, se crea. Sin embargo, coincido en que existen procesos de innovación, ruptura y continuidad. Por ello, considero que Hobsbawn analizó procesos de invención particulares que no configuran un modelo general capaz de utilizarse en el caso seri. Problema que discutiré en otro momento. Agradezco a Deborah Dorotinsky sus comentarios críticos y sugerencias en este sentido.

75. Moser, "Seri Basketry", I25-130.

76. Schindler, "The Material Culture", 408.

77. Moser, "Seri Basketry", I25, fig. I2b.

78. Schindler, "The Material Culture", 408.

79. Schindler, "The Material Culture", 4II,4I5, figs. I05, I06, y I09. 
detalladamente cada uno de los procesos de producción, ${ }^{80}$ no estaba organizado como un conjunto cerrado de saberes transmitido desde tiempos inmemoriales y preservado (mas no enriquecido) por las generaciones actuales.

$\mathrm{Al}$ igual que en otras tradiciones gráficas en América, ${ }^{8 \mathrm{I}}$ los procedimientos para la transmisión del conocimiento de los diseńos, tanto como sus contenidos concretos estaban abiertos al cambio. De ahí la relevancia y preocupación de las mujeres seris por generar de manera constante consensos parentales y colectivos fundamentados en la "tradición" para su transmisión, ya que, como advirtió Debbora Battaglia, ${ }^{82}$ al trabajar entre los sabarl en Melanesia, la cultura es un proceso y no un sistema cerrado de signos, y esto implica reconocer, por una parte, que no existe un conocimiento absoluto, fijo o estable que las personas reconocerían previamente a su construcción y, por otra parte, que existe un aura de estabilidad que permite controlar el flujo de tal construcción. Por ello, pese a esta abertura al cambio, las tejedoras seris distinguían entre diseños antiguos, diseños de reciente invención y diseños de origen pápago.

De acuerdo con algunos autores, el tejido de los diseños en la cestería inicia aproximadamente en $1900,{ }^{83}$ para otros, por su complejidad e importancia, no podría ser un desarrollo contemporáneo ${ }^{84} \mathrm{y}$ en tanto que hacía parte de la manufactura de los canastos ceremoniales, posiblemente fue una práctica que se abandonó durante la intensificación de las hostilidades entre los mexicanos y los seris durante el siglo XIX para retomarse a principios del siglo xx. ${ }^{85}$ Para las tejedoras de El Desemboque, el reconocimiento de un diseño como antiguo respondía a otros parámetros.

Por sugerencia de algunas mujeres seris y con el fin de ampliar su conocimiento sobre diseños, conformé una segunda base de datos con algunas fotografías de cestería de la Colección Etnográfica del Arizona State Museum (recolectadas entre 1921 y 2000). ${ }^{86} \mathrm{Al}$ observar las fotografías señalaron que

8o. Martínez, "Pensando a través de la cestería seri".

8I. Janet C. Berlo y Ruth B. Phillips, Native North American Art (Nueva York: Oxford University Press, 1998), 29; Cesarino, "A escrita e os corpos desenhados", iıo.

82. Debbora Battaglia, On the Bones of the Serpent. Person, Memory, and Mortality in Sabarl Island Society (Chicago y Londres: The University of Chicago Press, I990), Io.

83. McGee, Los seris, 289; Moser, "Seri Basketry", II7; Schindler, "The Material Culture", 390.

84. Johnson, "Seri Indian Basketry", II.

85. Moser, "Seri Basketry", I22.

86. En la muestra de esta colección sólo hay cuatro canastas de la década de los años veinte, es visible que durante la década de los años treinta y años posteriores a esta fecha proliferaron los diseños de estrellas, redes y flores. Entre 1940 y 1960 aparecen formas nuevas, como canastos 
todos estos cestos eran antiguos. Desde mi perspectiva, y aludiendo a un proceso gradual de figuración, podría describir sobre una línea temporal el desarrollo de algunos diseños como los saguaros o cactus, recolectados en 192I por Louis Wetherill (fig. 4a); en 1930 por James Mason (figs. 4b y 4c) y en 1948 por William Smith (fig. 4d) destacando con Moser ${ }^{87}$ el papel de la demanda comercial. Sin embargo, esto no parecía ser relevante gráficamente para las mujeres seris de El Desemboque. Más aún, conscientes de que eran manufacturados para la venta, los denominaban como antiguos y tradicionales. Esto confirma que para dar cuenta de qué son los diseños en la cestería es preciso ir más allá de un análisis formal.

El valor de antiguo estaba definido por la forma del canasto y su relación con contextos de uso o bien por el vínculo entre el diseño, el canasto y su utilización. Por ejemplo, indicaban que las canastas más antiguas eran aquellas que tenían forma de olla pues en ellas se almacenaban semillas. Posteriormente narraban experiencias personales sobre su vida en los campamentos y describían escenas de comensalidad. La falta de diseño o el diseño de círculos, espiral y zigzag también confirmaba la antigüedad del canasto, señalaban que ellas no tejerían un diseño en un canasto para usarlo y que, en consecuencia, las mujeres antiguas tampoco lo harían. Finalmente, lo antiguo se evaluaba a partir del proceso de manufactura del diseño, pero no así de sus cualidades gráficas. Éste fue el caso de los diseños cöcaafija (hecho con círculos) (fig. 3a) o cocpaaija (remolino) (fig. 3b), cuya evaluación radicaba en que técnicamente eran de fácil elaboración. Por tanto, eran los primeros que toda tejedora aprendía y los primeros que las mujeres antiguas debieron manufacturar.

Pese a que la apreciación de las mujeres de El Desemboque pueda ser paralela a nuestro registro visual, ya que en las primeras fotografías las canastas con diseños ${ }^{88}$ estaban tejidas con cöcaafija e incluso $\operatorname{Moser}^{89}$ reportó que María Luisa

cuadrados, así como diseños distintos y de mayor complejidad técnica, tal como los que Moser, "Seri Basketry", presenta en su artículo. Visita realizada del i al 7 de noviembre. Agradezco el apoyo de Carolyn O’Meara, de Diane D. Dittemore y Andrew T. Higgins, curadores de la colección etnográfica.

87. Moser, "Seri Basketry", 195.

88. García y Alva, Raza seri, 2I y 23. Estas fotografías son parte del reporte de la expedición a la Isla Tiburón de 1904 destinado al entonces gobernador de Sonora, Rafael Izábal, a quien se conoce por sostener los "diez años de la guerra de Encinas" con los seris (Spicer, "Seris", II4). Es preciso mencionar la nota al pie de las fotos donde aparecen "los canastos" y las mujeres que los sostienen sobre sus cabezas: "Mujeres seris detenidas por la Primera Avanzada de los Pápagos de la Expedición".

89. Moser, "Seri Basketry", II7. 

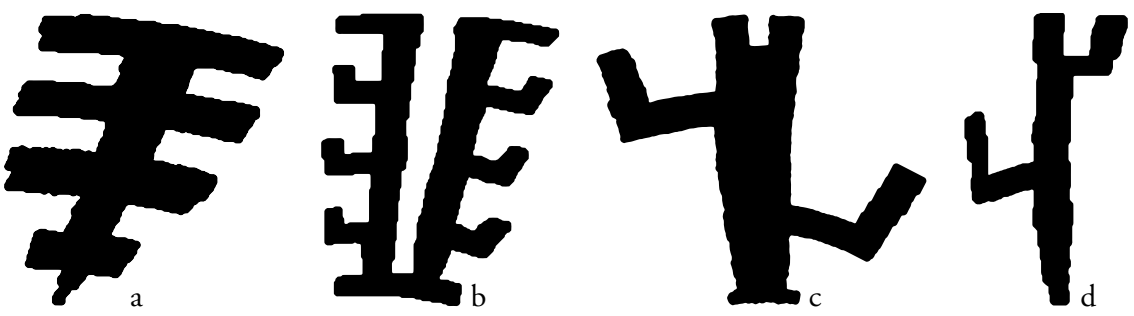

4. Diseños que presentan la figuración de los saguaros y cactus.

Chilón, mujer seri nacida aproximadamente en 1887 , consideró que la primera canasta decorada que observó fue en una fiesta de pubertad, quizá en I900, con el diseńo cocpaaija, ${ }^{90}$ la definición de lo antiguo es diferente. Para ellas lo relevante es cómo el diseño ha transformado la cestería en una técnica potencial de lazos sociales, ya que posiblemente la finalidad de la creación de estos objetos, como diría Lévi-Strauss, ${ }^{91}$ es ampliar el conocimiento sobre ellos, al dar un nuevo sentido empírico y conceptual a su estructura, y al mismo tiempo extender la realidad, en ocasiones de manera imprevista, a la que pertenecen.

Por este motivo, para las mujeres seris la evaluación de un diseńo como antiguo radicaba en un vínculo que desde el presente hacían con el pasado y no su inverso, funcionando de manera análoga a las marcas sabarl en Melanesia, donde lo relevante era la conexión social entre la imagen y su productor. ${ }^{92}$ Así, a diferencia de lo reportado por Moser, ${ }^{93}$ desde la perspectiva de las tejedoras seris, los nombres otorgados a los diseños responderían a un uso doméstico, ceremonial, comercial y antiguo al estar en un campo de transmisión del co-

90. Durante la década de los años veinte encontramos distintos registros visuales con estos mismos diseńos. En la colección etnográfica del Arizona State Museum hay un canasto en forma de olla, colectado en I92I por Louisa Wetherill con diseño cöcaafija. En algunas de las fotografías de Edward H. Davis, de 1924 y I925, quien trabajó como fotógrafo y coleccionista de objetos etnográficos para George G. Heye (Museum of the American Indian en Nueva York) de I9Io a I944, el único diseño identificable fue cocpaaija. Véase la fotografía OPI496I-534 con fecha de 1924, consultada el 20 de abril de 2015, www.sandiegohistory.org, Colección de Fotos de San Diego History Center Online y la fotografía I5/4246 colectada en 1925, consultada el 20 de abril de 20I5, www.nmai.si.edu, Colección de fotos del National Museum of American Indian. En el trabajo de Schindler, "The Material Culture", también hay fotos de canastos de la Heye's Foundation (HF I2/98I6) en forma de olla con diseńo cöcaafija (plate 98) que fueron colectados en I923.

91. Lévi-Strauss, "La ciencia de lo concreto", I06.

92. Battaglia, On the Bones of the Serpent, 6, 8.

93. Moser, "Seri Basketry". 

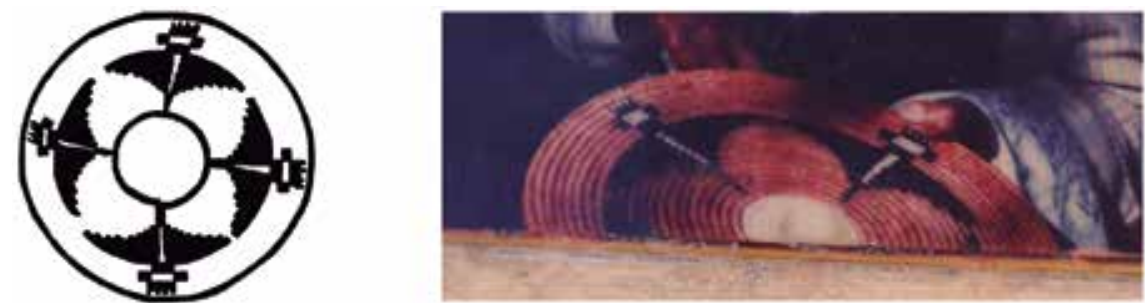

5. a) A la izquierda la fig. I2b de Moser, "Seri Basketry" (vid supra n. 4); b) a la derecha la reproducción de un detalle de una foto que muestra a la madre de Berta Estrella sosteniendo el canasto registrado por Moser. Colección personal de Berta Estrella, 2014.

nocimiento o de vinculación social en el presente, pues es ahí donde adquieren valor para sus poseedores — como señaló Pierre Déléage ${ }^{94}$ para los diseños en Amazonía- y no por los rasgos formales o estilísticos per se o por una relación ceremonial o mercantil que podría presumirse estática a lo largo del tiempo. Además, lo notable de la experiencia de las tejedoras sobre lo antiguo es que, una vez más, está relacionada con la transmisión de un conocimiento familiar, particularmente femenino.

Un ejercicio constante al mirar estas fotografías fue la identificación de las mujeres que habían manufacturado las canastas. Las tejedoras de El Desemboque destacaban que el reconocimiento se producía a partir de una experiencia empírica - estar presentes durante el tejido o venta de la canasta y en ocasiones me mostraban fotografías de sus colecciones personales para demostrarlo- o por una experiencia enseñada — recordaban que a esa mujer le gustaba tejer ese diseño o utilizar ciertos tonos para las fibras. Cabe recordar que, como señalé, estos dos procedimientos forman parte de la transmisión de la "tradición" y del conocimiento. Al mirar la imagen de Moser,"95 una mujer dijo: "esa canasta la tejió mi mamá", acto seguido me mostró una fotografía donde su madre la sostenía entre sus brazos (fig. 5b). Incluso, a esta canasta se le calificó como antigua. Por todo lo anterior, sugiero que para estas tejedoras seris la noción de lo antiguo, vinculada con la cestería, se articula con la memoria de los lazos parentales femeninos que desde el presente la mujer que manufactura los diseños crea con el pasado.

94. Déléage, "Les Pictographies narratives amérindiennes", ııо.

95. Moser, "Seri Basketry", fig. I2b, I26. 
Hasta este momento he mostrado cómo el lazo entre las designaciones de los diseños y los propios diseños es un índice de relaciones sociales que, por una parte, implica generar consensos familiares por la variación individual sobre la cual se fundamenta su producción-nominación y, por otra, involucra una nueva variación a nivel parental cimentada en la "tradición". Esto explicaría las ocho recurrencias en mi registro, ya que, desde esta perspectiva, conformarían un tipo de repertorio gráfico que las tejedoras reconocerían como "tradicional" y antiguo (figs. 3a-3h). Éste, antes que configurar un conjunto cerrado de diseños relacionados con nombres determinados que permanecería intacto a lo largo del tiempo, sería la expresión gráfica de vínculos de experiencia y práctica —empírica o transmitida - compartidos por distintos grupos familiares y fundamentados en la "tradición".

Aún queda por explorar ¿por qué los nombres otorgados remiten a la figuración (estrellas, flores, etc.)? Más aún, ¿por qué ésta es una forma de producción de diseños y cuál es el papel de la invención en este sistema de producción? Es preciso volver al problema inicial de este texto: la variación individual en la producción y denominación de los diseños. La finalidad es dar cuenta de cómo los diseños seris funcionan como técnicas de distinción entre las tejedoras y de intensificación de los vínculos sociales que mantienen con los no seris por medio de la venta de las canastas.

\section{Los diseños como técnicas de vinculación: distinción e intensificación}

La variación individual forma parte del proceso de transmisión y manufactura de la cestería. Ésta se produce durante la recolección del torote en el desierto, ya que por lo general las ramas cortadas suelen ser propiedad de cada mujer, y en los espacios de producción de la cestería, determinados por la composición de cada unidad habitacional ${ }^{96}$ y por la organización y uso que cada mujer

96. A principios de la década de los veinte, los seris se desplazaron gradualmente hacia un antiguo campamento permanente a orillas de Bahía de Kino (Spicer, "Seris," II6), dando inicio a un proceso de sedentarización que culminaría con el establecimiento de la cooperativa pesquera en El Desemboque en 1938 (Spicer, "Seris", II5); Felger y Moser, People of the Desert and Sea, I6. Entre 1974 y 1984, los gobiernos federal y estatal promovieron la construcción, tanto en El Desemboque como en Punta Chueca, de viviendas permanentes de block y concreto cuyo trazo obedecía a una cuadrícula urbana (Pérez Ruiz, "Seris", 80; Rentería, Seris, 30-3I), la cual hasta el día de hoy organiza estos poblados. Por este motivo, los espacios donde se manufactura la cestería 
hace de ellos. En tales espacios - conformados por áreas para cortar y preparar las ramas; quemarlas y producir tinturas; lavar, procesar las fibras y tejer- es posible ver a consanguíneas y afines intercambiando conocimientos y prácticas. Pese a que se reproduzca un canon familiar, durante el tejido de la cestería y la manufactura de los diseños cada tejedora genera un estilo personal. ${ }^{97}$ Como afirmó una mujer: "cada quien tiene su forma de hacer las cosas", ya que el objetivo de esta variación es producir distinción; es decir, el reconocimiento de un proceso creativo personalizado.

El siguiente método que propusieron las tejedoras seris para continuar con la indagación de los diseños fue realizar historias de vida, con las cuales elaboraríamos fichas para identificar sus canastas en las ventas. Pese a que las mujeres recordaban con alegría y orgullo cuáles fueron los primeros diseños que tejieron, en sus relatos destacaban que al adquirir experiencia la variación individual en sus diseños surgía de forma natural. Sin embargo, durante el aprendizaje y la transmisión del conocimiento, esta experiencia creativa también era percibida como algo construido..$^{98}$ Una mujer enseñaba a su hija cómo manufacturar el motivo de la mariposa (seenel) y ésta procuraba alargar las alas y modificar las antenas para generar su estilo. Simultáneamente intentaba recordar motivos de mariposa tejidos por otras mujeres, familiares y vecinas, con el fin de no hacer copias idénticas. $\mathrm{Al}$ mostrarme su canasto, esta aprendiz, recurriendo una vez a la experiencia donde la variación era algo natural que se incorporaba en un proceso creativo, me dijo: "aunque copien, los diseños siempre salen diferentes" (figs. 6a-d). Por esta razón, pese a que Schindler ${ }^{99}$ indicó que los diseños podían ser replicados porque, al no ser propiedad de una familia o de ciertos individuos eran compartidos, sumaría que cada diseño y cada motivo se experimentaba como producto de la creatividad de la mujer que lo manufacturó, tal y como Richard S. Felger y Mary B. Moser señalaron. ${ }^{100}$ Como advirtieron estos autores, esto no es un proceso de copia, sino de apropiación, mediante el cual la variación se crea para posteriormente incorporarse como algo natural.

se alternan con ramadas, particularmente durante el verano (para una descripción de las ramadas o hasóoma véase Felger y Moser, People of the Desert and Sea, II7-II9).

97. Moser, "Seri Basketry", I30; Martínez, "Pensando a través de la cestería seri".

98. Véase Wagner, The Invention of Culture, 36-37.

99. Schindler, "The Material Culture", $4 \mathrm{I} 6$.

I00. Felger y Moser, People of the Desert and Sea, 196. 

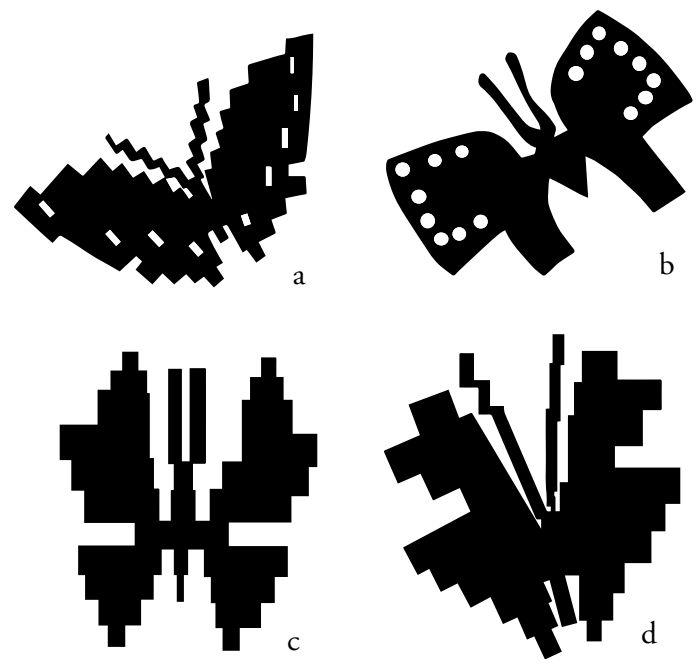

6. Variación de motivos de mariposa creados por algunas mujeres de El Desemboque, diseño de: a) María Luisa Molina;

b) Francisca Morales; c) Ana Victoria Rodríguez; y d) Ana Torres.

El campo para evaluar la producción de esta distinción es la belleza. ${ }^{\text {Ior }}$ Por ello, cuando las tejedoras exponen sus productos para vender esperan que quien los mira, sea un comprador o no, admire la belleza de su trabajo y tal vez no hacerlo sería una descortesía. ;Taziim ih! (¡qué bonito!) es una de las expresiones más comunes entre las mujeres, ya que quizá lo que se aprecia es la capacidad, creatividad, iniciativa e innovación individual plasmada en cada creación. Esta evaluación difiere de aquella del comprador, ya que las premisas sobre las que se fundamenta son distintas. Pese a que los coleccionistas suelen evaluar mercantil y estéticamente las piezas por la calidad del tejido, del tinte y los diseńos, para las tejedoras estas cualidades expresan la distinción individual que se genera por variación durante la manufactura y constituye una técnica de vinculación social. Inclusive la elaboración de los diseńos no necesariamente atiende la demanda del mercado. En mi registro, la mariposa era el diseño con mayor presencia y

IoI. En relación con otras categorías nativas de belleza en Amazonía para los kayapó véase Terence Turner, "Imagens Desafiantes: a Apropriação Kaiapó do Vídeo", Revista da Antropologia, vol. 36 (1994): 36. La belleza para los kayapó es la transformación de la naturaleza en cultura o bien la organización secuencial, repeticiones sucesivas del mismo padrón que con cada integración se aproxima a su perfección. También en México para los rarámuri véase María Isabel Martínez Ramírez, "Crear un mundo caminando", Artes de México. Tarahumaras. El camino, el hilo y la palabra, núm. I22 (20I4): 40, donde lo bello es análogo a lo bueno, donde proceder de manera colectiva y correcta se resume en el término wee gárá júku ("está bueno"). 
empero uno de los intermediarios me comentó que estaba un poco aburrido, era el que más emoción y entusiasmo causaba entre las mujeres.

Recordemos que los canastos no son objetos anteriores a su decoración, sino una totalidad que conjuga la plástica y la gráfica para crear un objeto nuevo. Como he mostrado en otro sitio, ${ }^{\mathrm{IO} 2}$ la producción de fibras, de tinturas y, en el caso que nos ocupa, los diseños tejidos en las canastas condensarían en su manufactura y figuración técnicas que generarían simultáneamente la distinción individual, la ampliación de las relaciones con otros seris (su "tradición" y lazos parentales) y con los no seris. Desde esta perspectiva es preciso indagar a quién están dirigidos los diseños.

Las tejedoras de El Desemboque, ${ }^{\mathrm{IO} 3}$ de acuerdo con mi reporte y visitas de investigación durante los inviernos de 2013 y 2014 en Bahía de Kino, Sonora; Ciudad de México y Tucson, Arizona; comercializaban sus canastos de forma personalizada en un mercado: a) local (El Desemboque, Punta Chueca y Bahía de Kino, Sonora) (fig. 7a); b) regional y nacional (Hermosillo, Sonora) (figs. 7 b y $7 \mathrm{c}$ ), donde por lo general asistían a ferias de artesanía organizadas por Fonart (Fondo Nacional para el Fomento de las Artesanías), el Museo de Culturas Populares y otras fundaciones privadas; y c) internacional (especialmente en el suroeste de los Estados Unidos de América), donde también vendían personalmente sus piezas y asistían a ferias o eventos bajo el apoyo de viajeros y voluntarios de asociaciones como William Penn House.

Dentro del primer circuito las mujeres solían vender sus canastos como parte de un conjunto más amplio de objetos: collares de concha, hueso, chaquira y tela, piezas talladas de palo blanco, palo fierro y coral negro, muñecas de tela, aretes de escama de pez, pulseras, entre otros. El Desemboque se ubica al norte del territorio seri y cuenta con dos vías de comunicación terrestres, ambas de terracería: la primera es costera y la conecta con Punta Chueca y Bahía de Kino, la segunda se vincula con una carretera, extensión de Calle 36 que enlaza Hermosillo y Bahía de Kino, cuyo punto intermedio es Puerto Libertad, pero que comunica con la ciudad de Caborca. ${ }^{104}$ Las condiciones inadecuadas para transitarlas permiten la presencia esporádica de visitantes locales como investigadores, estudiantes, trabajadores temporales e integrantes de organizaciones

IO2. Martínez, "Pensando a través de la cestería seri".

I03. Gutiérrez, "Cestería seri”, I73-I76, presenta una categorización diferente de los mercados para comercializar la cestería en Punta Chueca y El Desemboque: los campamentos o pueblos seris, Bahía de Kino y Hermosillo y los Estados Unidos de América.

I04. Marlett, "Introduction”, 36; Pérez Ruiz, Seris, 368. 
DOI: http://dx.doi.org/10.22201/iie.18703062e.2016.109.2579

I62

MARÍA ISABEL MARTÍNEZ RAMÍREZ

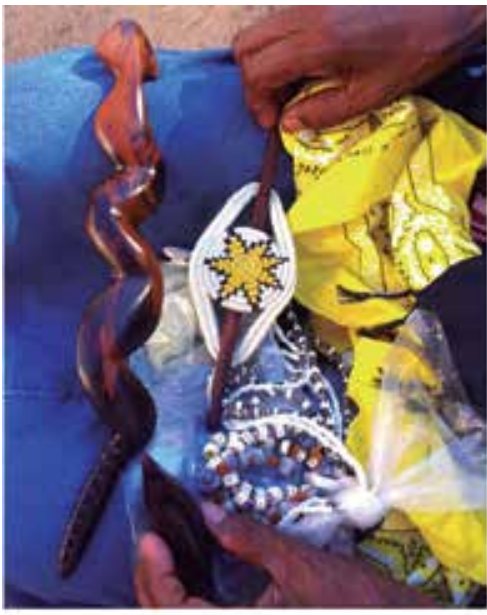

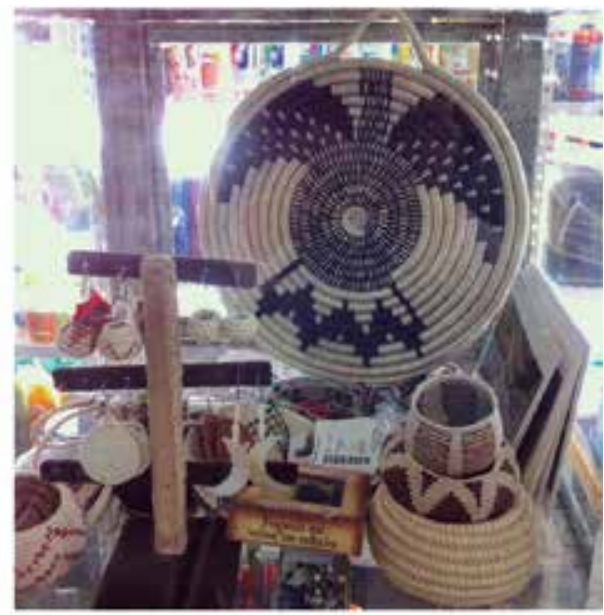

b

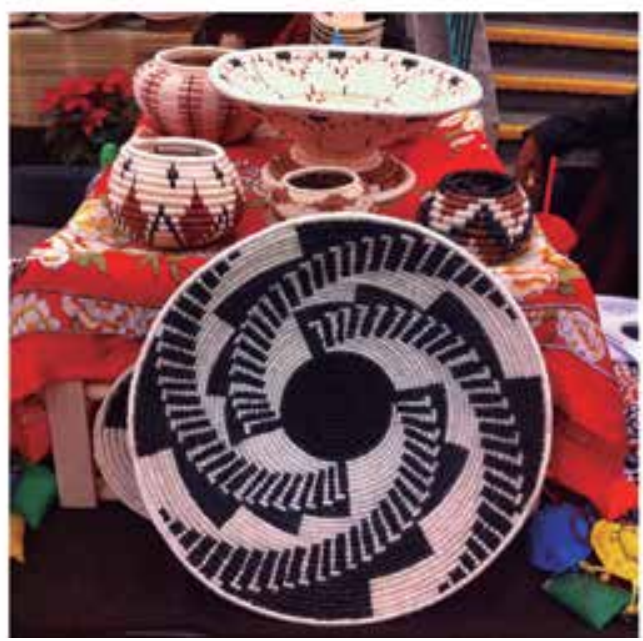

C

7. Contextos de venta de las mujeres seris de El Desemboque: a) María Luisa Molina muestra sus productos de venta; b) vitrina en un local en Bahía de Kino; c) exposición "El arte popular" en la Ciudad de México en diciembre de 20I4. Fotos: María Isabel Martínez Ramírez. 
no gubernamentales, quienes conforman un grupo de compradores potenciales. En ocasiones, las vendedoras no eran las productoras. La venta por consignación opera en todos los circuitos, particularmente en aquellos que requieren desplazamiento. Por último, una de las principales formas de venta es la participación en ferias internacionales y, en ocasiones nacionales, así como la venta directa a intermediarios de Native American art $^{\mathrm{10}}$ que desde hace décadas mantienen una relación personalizada de compra-venta con algunas tejedoras de El Desemboque.

Durante la manufactura, la variabilidad de los diseños — así como el procesamiento de fibras, tinturas y formas de la cestería— ${ }^{106}$ se articula con la distinción individual entre las tejedoras, evaluada a partir del campo de la belleza. Al ingresar en el circuito de venta, las seris han potencializado este sistema de producción de belleza al manufacturar canastas tejidas con diseños. Es decir, han ampliado las relaciones con los no seris mediante el intercambio y la compraventa, generando nuevas maneras de "alcanzar y crear lo real." Al igual que en los procesos de "intensificación cultural" (cultural enhancement) documentados en Nueva Guinea, ${ }^{107} \mathrm{al}$ innovar e inventar diseños, las mujeres han vigorizado sus mecanismos de distinción y variabilidad internos (sean individuales o familiares), al mismo tiempo que han expandido sus lazos con los no seris. Al ser una técnica para generar distinción individual y consensos familiares, la variabilidad en la producción y denominación de los diseños no sería un indicio de pérdida

I05. La vinculación de la producción de la cestería seri con los circuitos de venta debe enmarcarse en las exploraciones que durante finales del siglo xIx y principios del siglo xx, viajeros como W.J. McGee realizaron entre los seris - y en general en todo el noroeste mexicano y el suroeste de los Estados Unidos de América con la finalidad de coleccionar materiales de culturas que se presuponía no sobrevivirían. Esto produciría un interés generalizado en el sur de los Estados Unidos de América que, aunado al desarrollo de Bahía de Kino - como centro turístico y de pesca comercial entre las décadas de los ańos veinte y cuarenta- y al papel de intermediarios comerciales como Smith, propiciarían un mercado de Native American art que continúa activo bajo la forma de venta en ferias y museos en los Estados Unidos de América. Además, durante la década de los años setenta surgieron en México instituciones cuyo objetivo era el rescate y la revitalización de las artesanías, en tanto patrimonio cultural, que buscaron estimular la organización de talleres familiares para complementar sus ingresos. Pese a que éste no fue el caso seri, actualmente algunos circuitos de venta locales, regionales y nacionales precisan de la intermediación de instituciones públicas como el Fondo Nacional para el Fomento de las Artesanías (Fonart) y el Consejo Nacional de Culturas Populares. Véase Martínez, "Pensando a través de la cestería seri".

Io6. Martínez, "Pensando a través de la cestería seri”.

I07. Véase Richard Salisbury en Sahlins, "O 'pessimismo sentimental”, 53. 
cultural, carencia de significado o la expresión del estatus utilitario de las canastas; sino la manifestación del fortalecimiento de la producción y reproducción de la sociedad. En este sentido, cabe cuestionar en qué medida los seris hacían referencia a este proceso cuando calificaron como bellas sus pinturas faciales y los motivos pintados en la cerámica.

Ejemplo de esto es la producción mediante la innovación, entendida como la apropiación de diseños de una creatividad personal o familiar y proveniente de la variación generada durante la manufactura, la cual permite replicar motivos antiguos, "tradicionales" y de otras tradiciones gráficas, como la de los pápago. Una mujer tejió una canasta con el diseño cocömonjc (ondulado) (fig. 8a) basado en una fotografía que William Smith tomó en 195I en la Isla Tiburón — publicada por David Burckhalter- ${ }^{\text {ro8 }}$ indicando que su costo monetario sería más alto por su antigüedad. También fue el caso de otra tejedora, quien luego de apreciar la belleza de una foto de la colección etnográfica del Museo Nacional de Antropología, decidió tejer una canasta con un diseño análogo (fig. 8b). La finalidad era que la compráramos, estableciendo de esta forma lazos con su "tradición" y con nosotras. Por una parte, estos casos manifiestan que los diseños son técnicas de vinculación que articulan lo antiguo o la "tradición" con su valor en el mercado, al expresar que la relación con una mujer antigua y con un comprador son mutuas e indispensables, una es la condición de intensificación de la otra. En las canastas tejidas con diseños, literalmente se tejen lazos de alteridad internos y externos, una canasta no podría ser "tradicional" sin la que se ha tejido en el presente y sin la conexión que se crea hacia el pasado. Al mismo tiempo, reconocer un canasto como "tradicional" genera, como advertía Battaglia, ${ }^{\mathrm{IO} 9}$ un aura de estabilidad y continuidad. Por otra parte, estos diseños podrían ser dispositivos de memoria, entendida como la producción de vínculos que a partir de la variación individual y durante la manufactura crean las tejedoras desde el presente hacia el pasado.

Como advirtió Carlo Severi, ${ }^{\text {IIO }}$ al igual que para las pictografías de la Biblia Dakota sioux y las producidas por los indios de América del Norte que estuvieron en la prisión Fort Marion, Florida entre i873 y 1875, los diseños seris expresan no sólo las formas en que se transmite la memoria y la "tradición", sino

I08. David Burckhalter, "William Neil Smith and the Seri Indians", Journal of the Southwest 55, núm. I (2013): 76.

I09. Battaglia, On the Bones of the Serpent, 7.

IIO. Severi, "Une Forme mnémonique amérindienne", II4-I64. 

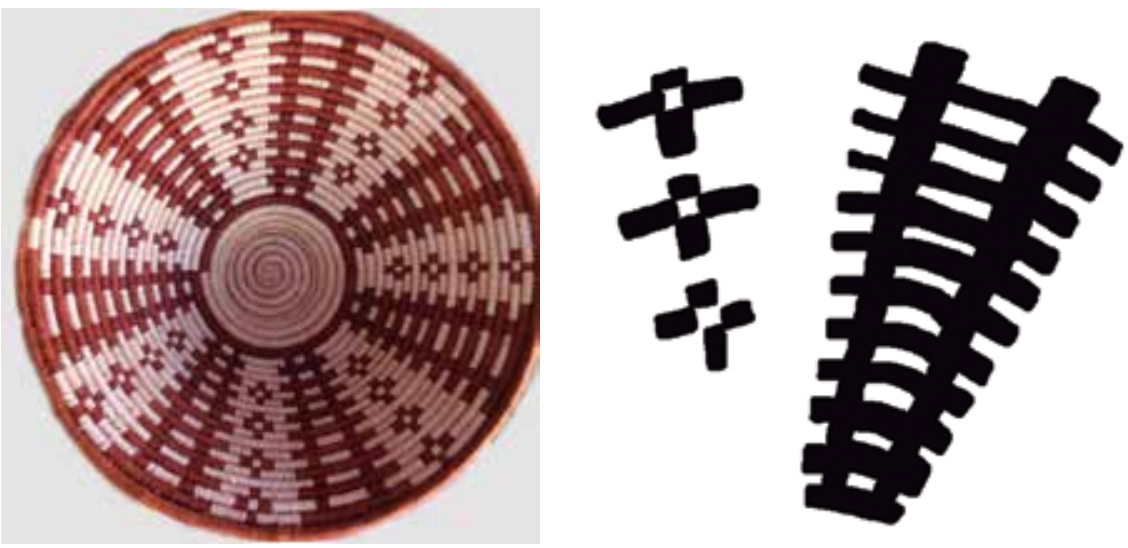

b
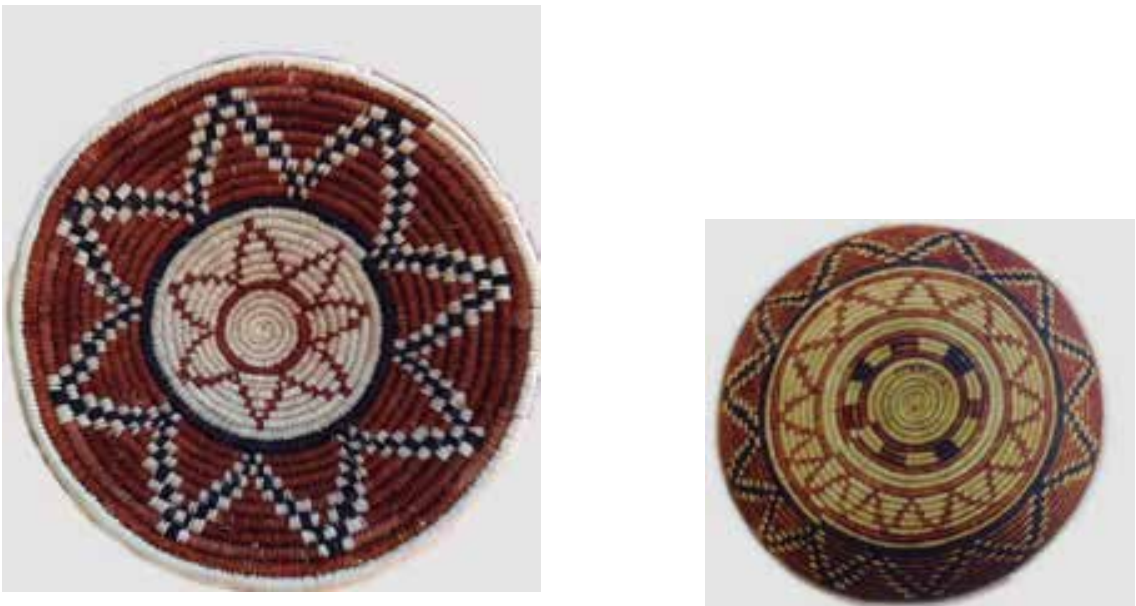

8. Ejemplos de innovación en los cuales se tejen relaciones de alteridad internas y externas, en: a) canasta con el diseño cocömonjc (ondulado), retomado de una fotografía de William Smith de I95I en la Isla Tiburón, tejida por María Luisa Molina. A la derecha se replica un dibujo del diseño original; b) a la izquierda, se muestra el canasto de Berta Estrella, quien replicó el diseño a partir de una foto de la Colección Etnográfica del Museo Nacional de Antropología, a su derecha. Fotos: María Isabel Martínez Ramírez. 
también cómo se crean. Al ser mnemotécnico, su espacio de organización no es exclusivamente visual, también se articula en la conciencia y se suma a los vínculos sociales que condensa y produce. Es posible que, al igual que para los sabarl de Melanesia, ${ }^{\mathrm{III}}$ la memoria no sólo sea una capacidad para recordar, sino una potencia productiva capaz de fijarse en los objetos. Por este motivo quizá el proceso de figuración de los saguaros o cactus no resultó gráficamente relevante para las tejedoras, ya que sean geométricos o figurativos, su importancia radica en la producción social (distinción individual), en la reproducción del colectivo (variación familiar por consenso y creación de la "tradición") y en la intensificación de su sociedad mediante su contacto con los no seris (potencia de distinción y variación). Además, como Severi señala para su caso, los diseños en la cestería seri también son creaciones individuales que fungen como identificación para reconocer a su productora en el tiempo así como dispositivos biográficos, ya que a partir de los vínculos que desde el presente se establecen con el pasado es posible recrear historias sobre las tejedoras y la forma de vida de otros seris no contemporáneos.

Finalmente, los diseños pápago o aquellos que provienen de otras tradiciones, luego de su identificación como fuentes de conocimiento externos, se incorporan a una creatividad individual o familiar. En la literatura, este proceso ha sido entendido como copia ${ }^{\mathrm{II} 2}$ o aprendizaje $\mathrm{e}^{\mathrm{II} 3}$ y como el resultado de la influencia que inició en los años veinte, luego de la relación de compra-venta que algunos coleccionistas privados como Edward H. Davis y William Smith entablaron con los seris. ${ }^{\mathrm{II}} \mathrm{A}$ partir de proveer a los seris de fotos y diseños pimas, papágos y apaches, los motivos de otras tradiciones gráficas del suroeste de los Estados Unidos de América se difundieron, modificando de manera radical su producción. ${ }^{\mathrm{II}}$ Así, surgirían representaciones zoomórficas y nombres de personas. ${ }^{\mathrm{II}} \mathrm{He}$ indicado que los repertorios gráficos seris y los procedimientos de su transmisión están abiertos al cambio. Y es posible que la incorporación de elementos exógenos en la cestería sea un proceso que no necesariamente inicia con su comercialización. ${ }^{\mathrm{II}}$

III. Battaglia, On the Bones of the Serpent, 8.

II2. Moser, "Seri Basketry", I30; Felger y Moser, People of the Desert and Sea, 196.

II3. Felger y Moser, People of the Desert and Sea, I95.

II4. Schindler, "The Material Culture", 416.

II5. Schindler, "The Material Culture", $4 \mathrm{I} 6$.

II6. Moser, "Seri Basketry", izo.

II7. Para un estudio arqueológico comparativo véase T. Bowen, “Seri Basketry: A Comparative View", The Kiva 38-3, núm. 4 (1973): I4I-I72. 
Desde la perspectiva de las tejedoras de El Desemboque, los motivos de otras tradiciones gráficas se incorporan en su creatividad por medio de la variación individual durante la manufactura de los diseńos y una creatividad familiar mediante la transmisión del conocimiento, la construcción del consenso parental y la "tradición". Por tanto, la innovación no expresaría degradación o ruptura, sino que sería una de las cualidades intrínsecas de este sistema de conocimiento y práctica. ${ }^{\mathrm{II} 8}$ Desde este punto de vista, es pertinente cuestionar a Schindler, ${ }^{\mathrm{II}}$ quien indicó que ante la transparencia de esta influencia externa, la innovación y la invención así como la individualidad seri, no se manifestaban en la creación de los diseños, reduciéndola a un proceso de copia y repetición. Afirmaciones que se contraponen con la experiencia de las tejedoras de El Desemboque.

Considero que el proceso de invención de los diseños y de sus denominaciones se articula con la figuración y, en consecuencia, con la potencia de apertura y elasticidad de la tradición gráfica de los seris; hecho que daría cuenta de por qué los diseños se nombran de tal o cual manera. Un ejemplo de esto es el diseño llamado ráama (fig. 9a) que asemeja la cuadrícula del juego de damas chinas, reportado por Moser ${ }^{120}$ como de reciente creación. La forma de producción de éste y otros diseños era reconocida por las tejedoras seris como una invención. Una mujer indicó que el diseño de la imagen IIg de Moser la inventó su madre y narró cómo durante días planeó la manufactura. Denominado por dos mujeres de El Desemboque como canasto en forma de balde con diseño de bolsa de red para colgar ollas con agua (liitro cool cöcoospoj), tanto la forma del canasto como el diseño tejido aludían a su función como contenedores de agua (fig. 9b). ${ }^{.2 I}$ De tal manera que, pese a que la forma y el diseño oscilaran entre lo "tradicional" y la invención — pues como demuestra una vez más este ejemplo, éstas no son posiciones opuestas sino constitutivas-, para las mujeres ambas eran figurativas. Por tal motivo, me enseñaron fotos del balde de metal y de la red. Éste también fue el caso de otra mujer, quien al relatarme cómo su madre inventó el diseño cocpaaija (espiral), describió que su objetivo era representar un ventilador. Inclusive, aún aludiendo a fuentes de conocimiento que las vinculaban con su entorno y las remitían a la "tradición", la figuración estaba presente. Una tarde, una tejedora me mostró unas almejas

II8. Véase Rena Lederman en Sahlins, "O 'pessimismo sentimental" ", 64.

II9. Schindler, "The Material Culture", $4 \mathrm{I} 6$.

I20. Moser, "Seri Basketry", I30.

I2I. Moser, "Seri Basketry", II9, imagen IIg. 

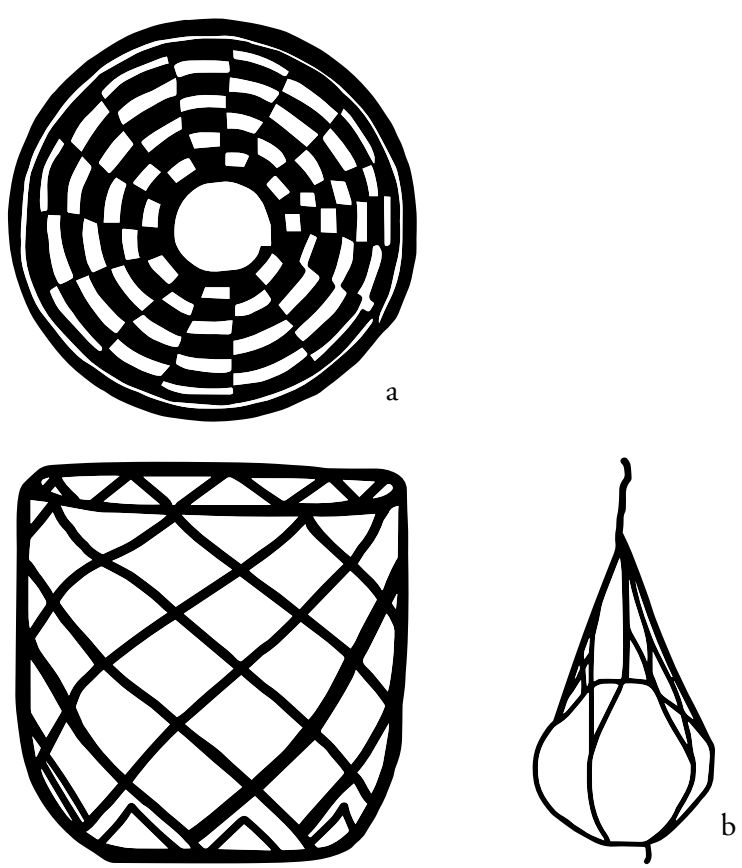

9. Ejemplos de figuración e invención: a) en el diseño denominado ráama figura la cuadrícula del juego de damas chinas, reportado por Moser, "Seri Basketry" (vid supra n. 4), fig. Isd; b) a la izquierda, dibujo de bolsa de red tomado de Moser y Marlett, Comcaac quih yaza (vid. supra n. 37), 222, a su derecha dibujo de un liitro cool cöcoospoj, diseño de bolsa de red, tomado de Moser, "Seri Basketry" (vid supra n. 4), fig. IIg.

piedreras (haxöl heecto, Leukoma grata) a la orilla de la playa para relatarme cómo las seris antiguas habían figurado en sus canastas los diseños que estos animales dibujaban en sus conchas, inventando motivos nuevos. ${ }^{122}$

I22. Por ejemplo, C. Marlett reportó que Raquel Moreno describió cómo una mujer usó el diseño de la concha oot icamazjij (Tivela byronensis), llamado haxöl hasaj o literalmente "almeja (diseño de) canasta", y una vez tejido lo nombraría haxöl yap "diseño de almeja canasta"; Cathy Moser, Shellson a Desert Shore. Mollusks in the Seri World (Tucson: The University of Arizona Press, 2014), I25. 
Aquello que trato de mostrar, por una parte, es que el reconocimiento posterior por analogía no se opone a la invención, sino que, como en el caso de la innovación, los motivos se incorporan a una creatividad propia a partir de vínculos individualizados de transmisión de conocimiento, memoria y "tradición". Por otra parte, al experimentarse como invenciones, cada tejedora genera una relación con los diseños, desde la cual otorga un nombre figurativo que materializa dicho vínculo individual. La figuración y la invención serían procedimientos de incorporación o apropiación a la memoria individual y a la "tradición". Esto explicaría la variación individual en mi registro léxico y en el de otros autores, ${ }^{123}$ fundamento de la producción social de los seris, según mi propuesta. A su vez, daría cuenta del porqué las mujeres de El Desemboque estaban tan preocupadas por crear consensos para transmitirme el conocimiento sobre sus diseños, pues aquello que está dado como natural ${ }^{124}$ es la individualidad, la variabilidad y el cambio y lo que debe construirse constantemente es el consenso en distintas escalas (familiar y colectivo) y la "tradición". Como Taylor advirtió para los shuar y achuar, también en este caso: "no se trata de [crear] una diferencia dentro del marco de una identificación, sino más bien de [generar] una identificación exacerbada dentro del marco de una diferenciación". ${ }^{125} \mathrm{Al}$ reflexionar sobre procesos de variación en la cestería de los rarámuri de Chihuahua advertí que la diferencia era mínima y que debía surgir desde dentro y no desde fuera, es decir, desde donde los canastos podían ser semejantes potencialmente, de lo contrario se corría el riesgo de alterar el modelo inicial. ${ }^{126}$ Para el caso seri y el descrito por Taylor, ${ }^{127}$ la diferencia está latente y debe reducirse de manera constante. Este contraste evidencia que ante objetos que podríamos caracterizar por su semejanza plástica como la cestería, la variación y la individualidad implicadas en su producción pueden ser diferentes.

El problema de la variación individual abrió así un campo de indagación donde los diseños en la cestería seri o, para decirlo de otra forma, las canastas tejidas con diseños serían técnicas de vinculación que articulan la producción de la sociedad seri (distinción individual evaluada mediante un sistema de belleza),

I23. Moser, "Seri Basketry", I24.

I24. Wagner, The Invention of Culture, 36-37.

I25. Taylor, "Les Masques de la mémoire", 320.

I26. Martínez, "Crear un mundo caminando"; Isabel Martínez, "Alteridad, multiplicidad y reversibilidad en clave rarámuri. Crónica de un viaje por la antropología del otro”, tesis de doctorado (Universidad Nacional Autónoma de México, 2012).

I27. Taylor, "Les Masques de la mémoire", 320. 
DOI: http://dx.doi.org/10.22201/iie.18703062e.2016.109.2579

170

MARÍA ISABEL MARTÍNEZ RAMÍREZ

su reproducción (variación familiar, creación de la "tradición") y la intensificación con los no seris por medio de la venta (sistema de belleza y distinción). Más aún, al ser parte de un sistema de relaciones sociales, la producción y existencia de algunos de estos vínculos depende de los otros, expresando que al igual que la plástica y la gráfica, las canastas tejidas con diseños no sólo son otro tipo de objetos sino la expresión de otro modo de conocimiento sobre el mundo, de pensarlo, recrearlo y actuar sobre él. ${ }^{128}$ is

I28. Lévi-Strauss, "La ciencia de lo concreto".

N.B. Agradezco el apoyo del proyecto papiIt ia4OoII3, coordinado por Carolyn O’Meara del Instituto de Investigaciones Filológicas, UNAM, "El léxico nominal en seri” de la DGAPA, UNAM; a las tejedoras seris que coprodujeron esta investigación, Francisca y Marta Morales, Ana Torres, Aurelia Molina, Martha Monroy, Berta Estrella, María Luisa Astorga, Ana Victoria Rodríguez, Adriana Estella Romero, Ángela Torres Cubias, María Luisa Molina, Genoveva Hoeffer Félix, Raquel Hoeffer Félix, María de Jesús Félix Molina (Carolina), Lourdes Hoeffer Félix. A Debora Perales y Karen Selene Rodríguez, traductoras seris y participantes en las entrevistas, así como a Miguel Estrella, entre otros, por el conocimiento que aquí describo. A Carolyn O'Meara y Cathy Marlett por las revisiones de cmiique iitom y sus valiosos comentarios, así como a Steve A. Marlett por su apoyo y asesoría lingüística durante el trabajo de campo. A los dictaminadores anónimos por sus atinadas críticas y sugerencias que dieron profundidad y precisión a mi texto. 